\title{
Lectura crítica de los catecismos de Astete y Ripalda
}

\author{
TERCERA PARTE
}

\section{CORRESPONDENCIA ENTRE AMBOS CATECISMOS}

Una vez efectuada la lectura de ambos textos de catecismo con sentido crítico, atribuyendo en cada caso la paternidad a su respectivo autor, estamos en condiciones de proceder a la visión conjunta de ambos catecismos, a fin de establecer las oportunas similitudes y diferencias.

La más somera lectura de los catecismos de Astete y Ripalda obliga a convenir en la gran coincidencia existente entre ellos. Por ello nada tiene de particular que ya desde antiguo haya habido intentos de explicar básicamente la doctrina cristiana procurando concordar las explicaciones de uno y otro, y ello por doble motivo: por recoger lo que en gran manera es común a los dos catecismos, y por poder responder a la singularidad de quien había estudiado uno u otro ${ }^{1}$.

A pesar de no ser nuevo el intento, la falta de sentido crítico con la aceptación indiscriminada de lo que se hallaba incluido en cada catecismo, obligaba hasta el presente a no tener excesivamente en cuenta las concordancias anteriores. Por otra parte, dichos intentos buscaban una coincidencia en la doctrina y en cambio apenas si se ocupaban de la génesis o la razón de ser de cada pregunta y su correspondiente origen histórico.

1. Santiago, José, García MAzo: El catecismo de la doctrina cristiana explicado, o explicaciones del Astete que convienen también al Ripalda. Valladolid, 1847. Hizo la primera edición en 1837. Ángél María de ARCos: Catecismo católico de la doctrina cristiana compuesto con Ripalda y Asteto revisados nuevamente y añadidos. Madrid 1896. Damián Bilbao UgarRiza: Catecismo del P. Ripalda completado con el Catecismo del P. Astete ordenado cíclicamente y ligeramente adicionado. Madrid 1931. Juan Antonio RuANo Ramos: Catecismo explicado que contiene la letra de los Catecismos del P. Astete y del P. Ripalda. Madrid 1940, 2. ${ }^{\text {a }}$ edición. 
Dedicamos esta tercera parte a hacer un estudio comparativo de los catecismos mencionados, pero teniendo a la vista la agrupación de preguntas correspondientes a cada autor, lo que procede no es establecer un paralelismo entre Astete y Ripalda, sino enfocar cada uno de los bloques correspondientes a la luz de los que les han precedido.

La cuestión no es sencilla, puesto que en todos los casos de coincidencias, se trata de supuestos con los que se puede estar o no de acuerdo. Para evitar que la aventura de unas hipótesis se dejara arrastrar por la imaginación, hemos procedido con el mayor rigor posible comparando la parte correspondiente a los dos autores y a los dos principales correctores. Hemos prescindido totalmente de otras adiciones más recientes incorporadas a cada uno de los textos de catecismo, y que apenas han alterado su estructura. Por otra parte están perfectamente diferenciadas y no ofrecen mayor problema.

Centrando la cuestión en torno a los cuatro bloques temáticos procedentes de Ripalda y Astete por una parte y de sus respectivos correctores, Juan Antonio de la Riva y Gabriel Menéndez de Luarca por otra, el primer problema es el cronológico. Si hubieran escrito en orden correlativo sobre un mismo libro, la cuestión no ofrecería mayores problemas. Pero encontramos dos textos diversos, cuyos respectivos núcleos arrancan de finales del siglo XVI; además, dos correcciones, posteriores en dos siglos.

Ello equivale a detectar una similitud entre los bloques de Ripalda y Astete, por su afinidad cronológica. Y otra semejanza entre los respectivos bloques de Menéndez de Luarca y De la Riva. Como además la influencia siempre va del escrito antiguo al más reciente, hay que estudiarlos teniendo a la vista las correspondientes preguntas que precedieron a cada uno de ellos. Finalmente, como cada uno de los correctores hizo añadidos a un texto determinado, partió de lo que en él estaba contenido, intentando mejorarlo, y no repitió lo que ya estaba dicho; pero sí pudo tomar otras preguntas complementarias del texto distinto al corregido por él.

Así, por ejemplo, Gabriel Menéndez de Luarca ha de ser contemplado como corrector de Astete, al que añade sus aportaciones. Para ello completa las preguntas o lagunas que encuentra en el texto de Astete, pero tiene también a la vista el texto de Ripalda, no para completarlo, sino para tomar de él aquello que estima merece la pena incorporar al catecismo de Astete. Por su parte, él influye en las correcciones que unos años después Juan Antonio de la Riva va a introducir en el catecismo de Ripalda, ya que marca un estilo que De la Riva va a seguir.

Tratando de esquematizar y simplificar las relaciones mutuas, el siguiente gráfico puede dar una idea aproximada de las influencias existentes entre cada uno de los cuatro redactores: 


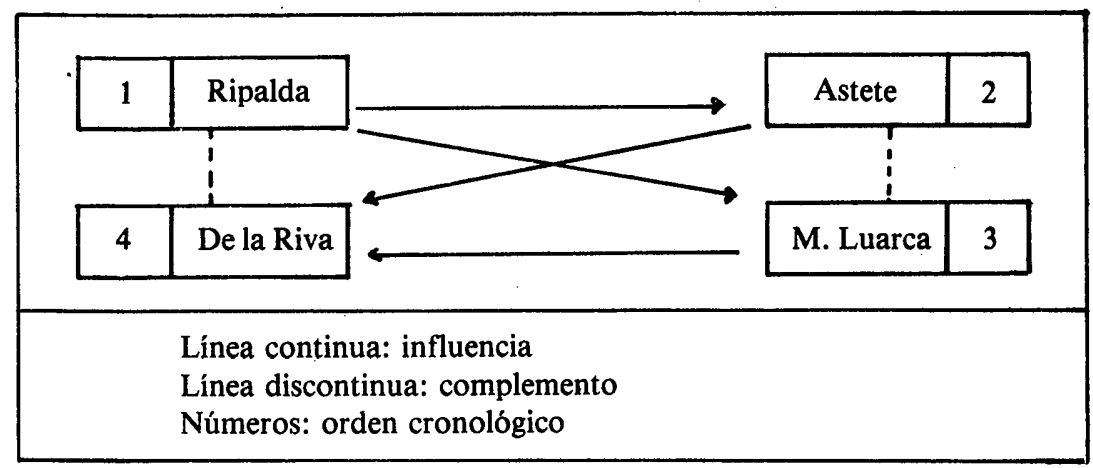

Según esto, hay que tener en cuenta el momento en que apareció cada intervención en el catecismo. En primer lugar, Ripalda escribió en 1586 como fecha segura y cuya primera edición conocida data de 1591. Le sigue Astete del que se tiene conocimiento de una edición de 1593, aunque él mismo afirma en 1592 haber escrito un catecismo para niños. En tercer lugar, Gabriel Menéndez de Luarca que hizo sus comentarios y añadidos a Astete en su catecismo mayor el año 1787, y que con anterioridad a esta fecha había escrito ya su catecismo menor, con el texto añadido, pero sin comentarios para adultos. Finalmente, Juan Antonio de la Riva había compuesto hacia el año 1790 sus añadidos al catecismo de Ripalda.

Además hay que tener presente la respectiva complementariedad (representada por las líneas verticales, discontinuas) formando un equipo RipaldaDe la Riva y Astete-Luarca.

Por último, es necesario contemplar la influencia directiva que los precedentes han ejercido sobre sus seguidores: Ripalda no ha recibido influencia de nadie al ser el primero de la serie, pero ha influido con toda seguridad sobre Menéndez de Luarca y quizá también sobre Astete (sobre ésta volveremos más adelante). Astete ha influido sobre Juan Antonio de la Riva. También Gabriel Menéndez ha ejercido un ascendiente sobre Juan Antonio de la Riva, quien por ser el último de la serie se ha limitado a recibir influjo de los demás.

Esto no resta singularidad a cada uno de los que han intervenido en la redacción de los textos de catecismo, tal como nos han llegado. Por eso, a la vez que contemplamos los aspectos comunes, vemos también la peculiaridad que distingue a cada uno en sus aportaciones.

Un caso especial preside las relaciones entre Ripalda y Astete. Hay una serie notable de similitudes y afinidades. Estudiadas detenidamente, no resulta fácil poder decir con precisión hasta qué punto Gaspar Astete tuvo a la vista el catecismo de Ripalda a la hora de redactar el suyo. A veces se trata de proximidad en el fondo de una cuestión; otras ocasiones la coincidencia está localizada en una expresión, una palabra o conjunto de ellas, demasiado destacadas como para que se trate de una coincidencia. Pero como no en todas las oca- 
siones la coincidencia es tan grande como para aparecer con toda evidencia y claridad, se abre paso la sospecha de que no se trata simplemente de peculiaridades personales propias de cada uno de los autores. Por eso, se intuye que ambos pueden haber bebido de una fuente común preexistente, de la cual tomarán lo mismo el fondo de algunas cuestiones como ciertas expresiones y formas redaccionales. Esto explicaría a la vez las coincidencias y divergencias. Pero tal hipótesis no se impone con tal fuerza como para excluir totalmente la influencia directa que Ripalda pudiera haber ejercido sobre Astete.

Como tal fuente común preexistente es una hipótesis no comprobada, cada uno es libre en esta cuestión de opinar según su criterio, a expensas de poder llegar un día a dar con ella, terminando por hacer luz en un asunto que aún permanece en la penumbra.

Ahora bien, en caso de admitir esa posible fuente común, el gráfico anterior tendría que sufrir una modificación, no sólo en el sentido de suprimir la influencia de Ripalda hacia Astete, sino en el sentido de que los dos recibieran una cierta aportación de algún autor o catecismo anterior que hemos denominado genéricamente como fuente común, a la espera de poder llegar a localizarla por comparación con los catecismos anteriores del siglo XVI. El gráfico tendría que quedar así:

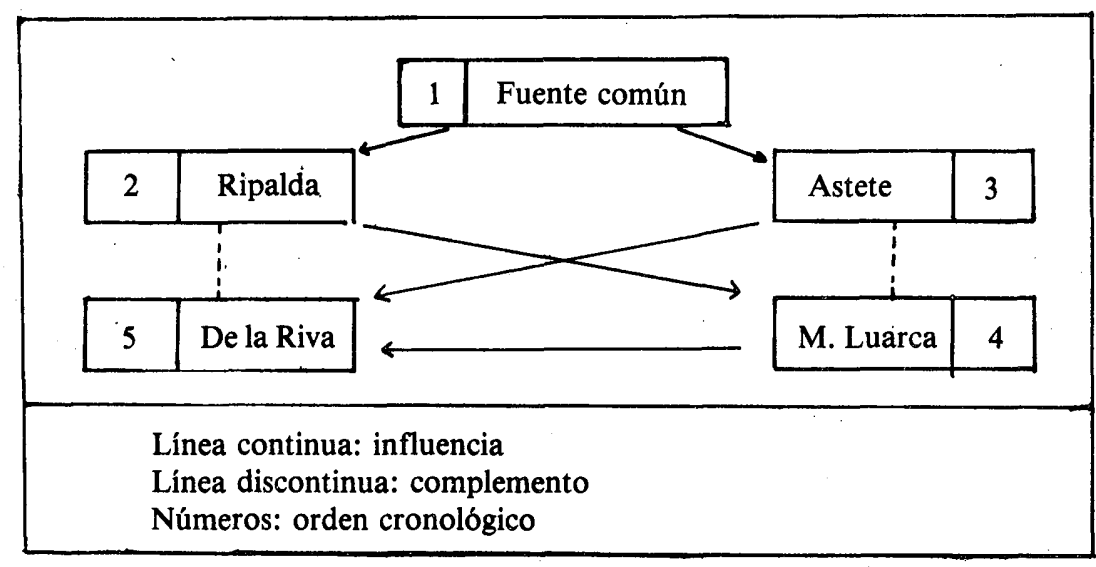

El resto de las influencias no ofrecen ese margen que la relación RipaldaAstete deja a la duda. Por eso, estudiaremos las claras influencias RipaldaMenéndez de Luarca, Astete-De la Riva y Menéndez de Luarca-De la Riva. No volvemos a la cuestión de los complementos de Menéndez de Luarca hacia Astete ni De la Riva hacia Ripalda, por haber sido ampliamente expuestos en las dos partes anteriores del presente trabajo. 


\section{LECTURA PARALELA DE AMBOS CATECISMOS}

Para estudiar la correspondencia existente entre los dos textos y la parte correspondiente a cada uno de los cuatro redactores principales, hubiéramos podido seguir el procedimiento de aislar sus aportaciones respectivas y tratar al final de compararlas. Ello se prestaba a demasiada confusión.

Por eso hemos preferido el sistema de ir haciendo una lectura en paralelo teniendo a la vista la parte correspondiente a cada uno de los bloques, valorando las coincidencias y destacando la singularidad específica de cada autor. Con ello quedan resaltadas aquellas partes de su intervención que les son peculiares.

Ya de por sí resulta bastante significativo que Ripalda y Astete escribieran casi a la vez y que ocurriera otro tanto al cabo de dos siglos con De la Riva y Menéndez de Luarca. Ello apunta incuestionablemente a una oferta de presentación de la doctrina cristiana que respondiera a la necesidad del final del siglo XVI; y a una adecuación y complemento para hacer una transmisión íntegra de la fe de acuerdo con los esquemas válidos a finales del siglo XVIII.

La similitud en el método de preguntas y respuestas obedece a un esquema previamente establecido y aceptado en la mayor parte de los casos como normal en los catecismos. En cambio, aun siguiendo el mismo método. Astete plantea el diálogo entre tres personas, de las que dos llevan el protagonismo mientras que un tercer personaje se limita a unas discretas y aisladas intervenciones. Ripalda no sigue el mismo esquema y su diálogo discurre entre dos personajes, el educador y el educando; además añade algunas advertencias que acompañan el diálogo, y que con posterioridad a él fueron aumentadas.

Los dos catecismos están divididos en cuatro partes y en el mismo orden, aunque en el caso de Ripalda, hay que hacer la salvedad de que en los versos iniciales, que describen las obligaciones del cristiano, enuncia otro orden. Ello puede ser debido a que los mencionados versos no sean originales de Ripalda, sino que empleara una fórmula preexistente. Lo que es una sospecha para estos versos que marcan las obligaciones del cristiano, se confirma más aún con los versos de introducción a la doctrina cristiana que comienzan con «Todo fiel cristiano...": no parece demasiado probable que fueran originales de Ripalda y hubieran sido copiados por Astete, puesto que su catecismo no consiste en una reprodución servil del de Ripalda.

Ello viene corroborado porque en el caso de la explicación del Símbolo de la fe, Ripalda prefiere seguir el orden que sugieren los artículos de la fe, mientras que Astete escoge el del Credo. Y aunque ambos explican lo mismo, difieren en la manera de hacerlo.

Se distinguen los dos textos entre sí en el contenido de las oraciones y formularios que ordinariamente todas las ediciones colocan al principio. Los dos catecismos no traen totalmente las mismas oraciones. Pero en cambio en los dos se da la inclusión muy tardía (a comienzos del siglo XX) del Gloria. Ya in- 
dicamos al estudiar el texto de Ripalda que ni los formularios ni las oraciones iban al comienzo sino integradas armónicamente en el texto, el cual suponía una explicación de la oración que acababa de incluir. No hemos podido comprobar lo mismo respecto a Astete, por no habernos podido remontar a las primeras ediciones. Sin embargo, cabe la sospecha de que haya sido así también, puesto que en las Bienaventuranzas después de formularlas, pregunta: ¿Qué hemos dicho ahora?: exactamente la misma pregunta que encontramos en Ripalda a continuación de cada formulario. Ahora bien, no es absolutamente seguro que en el catecismo de Astete las oraciones fueran colocadas formando parte del texto, porque el indicio que permite sospecharlo en las bienaventuranzas parece formar parte de un conjunto que se encuentra repetido en los dos catecismos casi con total exactitud; por ello pudiera ser un vestigio de la fuente común preexistente a que hemos hecho referencia.

La incorporación de un devocionario final (posteriormente enriquecido y aumentado) es común a ambos catecismos.

Respecto al apartado introductorio titulado en el catecismo de Astete como «División de la Doctrina Cristiana», detectamos una particularidad: Ripalda habla de que «estamos obligados a saber y entender» todo lo contenido en la división de la doctrina cristiana en cuatro partes. En cambio, Astete sólo centra su atención en el primer término hablando de las cosas que «está obligado a saber el cristiano». Será Gabriel Menéndez de Luarca quien tomando la anotación de Jerónimo de Ripalda la introduzca en el texto por él corregido.

Ripalda presenta en este lugar de su catecismo unas preguntas de corte ignaciano sobre el fin último del hombre. Tales preguntas están ausentes en Gaspar Astete, pero serán recogidas por Menéndez de Luarca para introducirlas en sus correcciones en el momento de hablar de la creación del hombre.

Finalmente, coinciden Ripalda y Astete en la misma división de la doctrina cristiana (credo, oraciones, mandamientos y sacramentos); pero mientras Astete dedica una pregunta para cada uno de ellos, Ripalda por su parte incluye en una sola pregunta lo relativo a mandamientos y sacramentos bajo el enunciado genérico de «¿Cómo obrar?». En la respuesta diferencia ambos aspectos al decir: «Entendiendo bien los mandamientos que hemos de guardar, y los sacramentos que hemos de recibir».

\section{CREDO}

Jerónimo de Ripalda y Gaspar Astete parten del origen apostólico del credo al comenzar su exposición, coincidiendo incluso en las expresiones. Igualmente coinciden en remitir como fuente de la revelación a la autoridad de Dios y a la mediación transmisora de la Iglesia, aunque en este caso las formulaciones sean diferentes:

Ripalda: - ¿De dónde sabéis vos haberlas dicho Dios» De nuestra Madre la Iglesia regida por el Espíritu Santo. 
Astete: $\quad-i$ Por qué lo creéis? Porque Dios nuestro Señor así lo ha revelado y la Santa Madre Iglesia así nos lo enseña.

De ahí pasan ambos a tratar de la relación existente entre el credo y los artículos de la fe, puesto que son dos cristalizaciones sobre el mismo contenido. A partir de aquí comienza la divergencia en cuanto al esquema seguido y que ya hemos apuntado anteriormente. Es el momento de contemplar una modificación que ninguno de sus predecesores había tenido en cuenta y que Juan Antonio de la Riva añade al catecismo de Ripalda al preguntar por las cinco cosas que contiene el credo en su formulación y que no están expresamente enunciadas en los artículos de la fe.

Además otra divergencia que se aprecia aquí es que al hablar de la aceptación por la fe, Astete incluye una explicación acerca de la fe, que está ausente del texto de Ripalda en idéntico lugar, puesto que lo va a tratar expresamente en el apartado que dedica a las virtudes teologales.

$\mathrm{Al}$ exponer quién es Dios casi hay una coincidencia total en las expresiones de Ripalda y Astete, excepto en una frase con que Astete introduce la respuesta y la supresión del atributo de «justo» por parte de Ripalda. Con esta salvedad, ambos describen los mismos atributos de Dios: todopoderoso, criador, salvador y glorificador (aunque Ripalda no lo menciona expresamente), así como el que carece de cuerpo.

Ripalda: -Dijisteis que el primero es creer en Dios; ¿qué entendéis vos por Dios? Un Señor infinitamente bueno, sabio, poderoso, principio y fin de todas las cosas.

Astete: $\quad-i$ Quién es Dios nuestro Señor? Es una cosa lo más excelente y admirable que se puede decir ni pensar, un Señor infinitamente bueno, poderoso, sabio, justo, principio y fin de todas las cosas.

Aunque sólo Astete menciona expresamente, también Ripalda habla de la Trinidad y de la distinción existente entre las tres personas para diferenciarlas entre sí y evitar los equívocos y confusiones. Solamente Gabriel Menéndez de Luarca se ocupa de la cuestión sutil del número de personas, naturalezas voluntades y entendimientos que hay en Dios pretendiendo completar el catecismo escrito por Astete.

Una singularidad propia de Jerónimo de Ripalda consiste en que se ocupa de la gracia al hablar de Dios salvador, haciendo un inciso al que dedica cuatro preguntas sobre la gracia. Astete tratará de ello al comienzo de los sacramentos, coincidiendo básicamente en las expresiones, como veremos en su momento.

\section{ENCARNACIÓN}

Ripalda y Astete divergen en la manera de preguntarse acerca de la encarnación; la razón estriba en que Ripalda había preguntado ya por la persona de 
Cristo al comienzo del catecismo al hablar de que el cristiano es el hombre que tiene la fe de Cristo. Le presenta como Dios y hombre, como el Mesías esperado con los oficios de Salvador y Maestro.

Es precisamente en este lugar del catecismo de Ripalda en el que Juan Antonio de la Riva ha copiado literalmente dos preguntas de Astete acerca del nombre de Jesús y el sentido de la salvación que nos trae, pero siguiendo la pauta marcada por Ripalda no las coloca al hablar de la encarnación, sino en la cuña que sobre Cristo contiene el comienzo del catecismo.

En cambio, con la diferencia de lugar ya mencionada, Ripalda y Astete tratan del significado del nombre de «Cristo», coincidiendo en la explicación aunque difieren en la forma de hacerlo:

Ripalda: - ¿Por qué se llama Cristo? Por la unción y plenitud de gracia que tiene sobre todos.

Astete: $\quad-i$ Qué quiere decir Cristo» Ungido

- ¿De qué fue ungido? De las gracias y dones del Espíritu Santo.

De acuerdo con el orden de los artículos de la fe, al tratar Ripalda la cuestión de la encarnación, dedica dos preguntas, una a la concepción de Jesús y otra a su nacimiento, mientras que Astete sólo pregunta por la concepción (de la cuestión del nacimiento de Jesús se ocupará Gabriel Menéndez de Luarca). Hay una curiosa coincidencia que puede ser debida al influjo de Ripalda sobre Astete, $\mathrm{o}$ al hecho de depender ambos de una fuente común, puesto que ambos emplean la expresión «sobrenatural y milagrosamente». Ripalda la emplea aplicándola al nacimiento y haciéndola extensiva a la concepción. Astete la aplica a la concepción de la que únicamente se ocupa.

Ripalda: $\quad-i$ Cómo fue de nuevo concebido siendo eterno? Tomando Cuerpo y Alma racional, no por obra de varón, sino milagrosa.

- ¿Cómo pudo nacer de Madre Virgen? Sobrenatural y milagrosamente, como fue concebido.

Astete: -Cristo nuestro Señor, ¿cómo fue concebido y nació de Madre Virgen? Obrando Dios sobrenatural y milagrosamente.

La influencia de Ripalda sobre Astete se adivina en la pregunta sobre la virginidad perpetua de María, literalmente exacta en las redacciones originales, aunque después haya sido transformada por la matización metodológica introducida por Daniel Llorente en el catecismo de Astete:

Ripalda: $\quad-i Y$ su Madre vivió después Virgen? Sí, Padre, perpetuamente.

Astete: $\quad-i S u$ Madre vivió después siempre virgen? Sí, Padre, perpetuamente.

D. Llorente: - ¿Su madre vivió después siempre virgen? Su madre vivió virgen perpetuamente.

Gabriel Menéndez de Luarca añade a Astete, y Juan Antonio de la Riva, siguiéndole, hace lo propio con Ripalda, una serie de cuestiones que derivan hacia el constitutivo esencial de Cristo inquiriendo por sus naturalezas, enten- 
dimientos y voluntades, personas y memorias, aunque cada uno de ellos en sus respectivas cuestiones cambie el orden y la forma de hacer las preguntas. (Recordemos que únicamente Gabriel Menéndez de Luarca se había ocupado de cuestiones semejantes al tratar de la entidad de Dios).

Se da una coincidencia asombrosa en las explicaciones de Menéndez de Luarca y De la Riva acerca de cómo se realizó la concepción de Cristo y cómo se produjo su nacimiento con la imagen del sol atravesando el cristal. Enseguida se piensa en la influencia del primero respecto al segundo:

M. Luarca: ¿Por qué decís sobrenatural y milagrosamente? Porque Jesucristo ni fue concebido ni nació como los demás hombres.

-Pues, ¿cómo se obró el misterio de su concepción? En las entrañas de la Virgen María formó el Espíritu Santo de la purísima sangre de esta Señora un cuerpo perfectísimo, crió de la nada un alma y la unió a aquel cuerpo; y en el mismo instante a este cuerpo y alma se unió el Hijo de Dios; y de esta suerte, el que antes era sólo Dios, sin dejar de serlo, quedó hecho hombre.

- ¿Y cómo nació milagrosamente? Saliendo del vientre de María Santísima sin detrimento de su virginidad, a la manera que el rayo de sol sale por un cristal sin romperlo ni mancharlo.

De la Riva: -Decid el Misterio de la Encarnación. Vino el Arcángel San Gabriel a anunciar a nuestra Señora la Virgen María, que el Verbo Divino tomaría carne en sus entrañas, sin detrimento de su virginal pureza. $Y$ luego el Espíritu Santo formo de la sangre purísima de la Virgen un Cuerpo de un Niño perfectísimo; y criando un Alma nobilísima, la infundió en aquel Cuerpo; y en el mismo instante el Hijo de Dios se unió a aquel Cuerpo y Alma racional, quedando, sin dejar de ser Dios, hecho Hombre verdadero.

- ¿De qué manera fue eso? (el nacimiento) Saliendo del vientre de la Virgen como el rayo del sol por el cristal, sin romperlo, ni mancharlo.

La lectura de las preguntas transcritas hace aparecer a primera vista la profunda similitud de conceptos y a veces también en las expresiones. Como diferencias entre ellas se aprecia la cuestión de Menéndez de Luarca sobre la singularidad de la concepción de Cristo respecto a la de los demás hombres; y la introducción de De la Riva sobre el anuncio llevado a cabo por el arcángel Gabriel. A pesar de tales diferencias, una tal semejanza difícilmente tiene explicación sin aceptar la influencia que Gabriel Menéndez de Luarca haya podido ejercer sobre Juan Antonio de la Riva.

\section{REDENCIÓN}

Las preguntas sobre la redención difieren en Astete y Ripalda. Este dedica más atención a la materia, mientras que aquél sólo le dedica una pregunta sobre la muerte en la cruz. Muy posiblemente Gabriel Menéndez tenía a la vis- 
ta el texto de Ripalda a la hora de hacer su corrección no sólo porque toma de aquél el calificativo de «eterna» para la muerte considerada como consecuencia del pecado, sino también porque casi con las mismas palabras repite la pregunta de Ripalda sobre el modo de incurrir en la pena del pecado:

Ripalda: $\quad-i$ Cómo incurrimos en ella? Pecando Adán, nuestro primer padre, en quien todos pecamos.

M. Luarca: -Pues, ¿cómo incurrimos en ella? Pecando nuestro primer padre Adán en quien todos pecamos.

Dos preguntas iguales dedican Ripalda y Astete a la cuestión del descenso de Cristo a los infiernos. Cabe pensar en la influencia de aquél en éste:

Ripalda: $\quad-i$ Cómo bajó? Con el Alma unida a la Divinidad

-Y su Cuerpo, ¿cómo quedó? Unido con la misma Divinidad.

Astete: $\quad-i$ Cómo bajó? Con el alma unida a la divinidad.

-Y su cuerpo, ¿cómo quedó? Unido con la misma divinidad.

Además Astete había dedicado otra pregunta al descenso de Cristo al infierno, sobre el sentido general encerrado en el concepto de «infierno», que luego ha sido introducida por mano anónima en el catecismo de Ripalda y que resulta más esquemática que la redactada por Astete.

Por su parte, Menéndez de Luarca en el catecismo de Astete y un redactor anónimo anterior a De la Riva en el catecismo de Ripalda coinciden en ampliar la cuestión del descenso de Cristo. Pero mientras Menéndez de Luarca enumera los «infiernos» y los describe después, el redactor anónimo da una definición conjunta para los cuatro infiernos tradicionales y luego describe uno a uno todos ellos. De la lectura comparada de las dos redacciones la impresión que se desprende no es la de un influjo de uno en otro, sino la de que los dos correctores han recurrido a las explicaciones tradicionales sobre la materia.

Respecto a la resurrección de Jesús, hay una gran similitud en las aportaciones que Ripalda y Astete hacen a la materia, con la única diferencia de que Astete añade que Jesús ha resucitado «para nunca más morir». En cambio, en la ascensión al cielo, es Ripalda el que aporta un dato que no figura en Astete porque éste ya lo había hecho constar: Ripalda dice que Jesús asciende «inmortal».

La glorificación de Cristo a la derecha del Padre es desarrollada en unos términos casi idénticos por Astete y Ripalda, aunque difieran originariamente en el número de preguntas; sin embargo, como ya hemos indicado, las dos de Ripalda quedaron fundidas en una sola pregunta en posteriores ediciones.

La resurrección de todos los hombres y el juicio final van incluidas en los escritos originales de Astete y Ripalda. Existe entre ellos diversidad de orden de las preguntas así como también en su redacción. Además conviene recordar que aunque Ripalda incluyera el juicio final en su catecismo, le fue suprimida dicha pregunta posteriormente, substituyéndola por una larga serie de cues- 
tiones minuciosas a cargo de Juan Antonio de la Riva. Tales preguntas de De la Riva no tienen parecido alguno con la pregunta que Menéndez de Luarca añadiera a Astete sobre Dios remunerador.

La similitud de respuestas a la cuestión de la comunión de los santos obliga a pensar en una influencia de Ripalda sobre Astete (o en la fuente común a ambos):

Ripalda: $-¿ Q$ Qué creéis cuando decís: creo la comunión de los Santos? Que los unos fieles tiene parte en los bienes espirituales de los otros, como miembros de un mismo cuerpo.

Astete: $\quad-¿$ Qué creéis cuando decís creo la comunión de los santos? Que los fieles tienen parte en los bienes espirituales de los otros, como miembros de un mismo cuerpo, que es la Iglesia.

La última frase de Astete le da pie en su catecismo para introducir sendas preguntas por la Iglesia y por el Papa. Esto ha sido tratado por Ripalda al iniciar la explicación de los mandamientos de la Iglesia:

Ripalda: $\quad-i Q u e ́$ cosa es Iglesia? La Congregación de los fieles, regida por Cristo, y el Papa, su Vicario.

- ¿Quién es el Papa? El Romano Pontífice, a quien debemos entera obediencia.

Astete: - ¿Quién es la Iglesia? La congregación de los fieles cristianos, cuya cabeza es el Papa.

- ¿Quién es el Papa? El Sumo Pontífice de Roma, Vicario de Cristo en la tierra, a quien todos estamos obligados a obedecer.

Se aprecia similitud de conceptos y aun de expresiones, aunque el orden sea diverso. Ripalda tiene un matiz propio muy importante al señalar que es Cristo quien rige la Iglesia. Astete se limita a dejarlo velado.

En cambio la originalidad de Astete le mueve a interesarse por las enseñanzas no contenidas en el Credo ni en los artículos de la fe. Dos siglos después se va a fijar en ella Juan Antonio de la Riva para introducirla en el catecismo de Ripalda:

Astete: -Además del Credo y los Artículos, ¿creéis otras cosas? Todo lo que está en la Sagrada Escritura y cuanto Dios tiene revelado a su Iglesia.

De la Riva: -Además del Credo y los Artículos, ¿creéis otras cosas? Sí, Padre, cuanto contiene la Sagrada Escritura, y Dios ha revelado a su Iglesia.

\section{PADRENUESTRO Y ORACIÓN}

Las primeras preguntas de Astete y Ripalda sobre la materia coinciden en gran manera hasta el punto de que dos preguntas son literalmente iguales; tan sólo se observa un distanciamiento en el sentido de que Astete habla de quién «dijo» el padrenuestro, mientras Ripalda habla de quién le «ordenó». Para 
observar mejor el paralelismo, desplazamos ligeramente de su lugar una pregunta del catecismo de Astete que éste incluye un poco más adelante inmediatamente antes de iniciar la explicación detallada de la oración del padrenuestro:

Ripalda: $\quad-i$ Quién ordenó la Oración del Padre nuestro? El mismo Cristo a petición de los Apóstoles.

- ¿Para qué? Para enseñarnos a orar.

- ¿Qué cosa es orar? Levantar el corazón a Dios, y pedirle mercedes.

Astete: -Decid: ¿Quién dijo el Padre Nuestro? Jesucristo.

- ¿Para qué? Para enseñarnos a orar.

- ¿Qué cosa es orar? Es levantar el corazón a Dios y pedirle mercedes.

- ¿Por qué? (es la mejor oración) Porque la dijo Cristo por su boca, a petición de los apóstoles.

Tres preguntas genuinas de Ripalda se fijan en la consideración de Dios como Padre, la filiación de que nos ha hecho objeto y una perspectiva que desborda el marco individualista del conjunto del catecismo y se fija en la común fraternidad de los hijos de Dios. Están ausentes en Astete.

Vuelven a coincidir al preguntar con quién se habla al rezar el padrenuestro, aunque Astete habla de Dios «nuestro Señor» y Ripalda se refiere a Dios «nuestro Padre»:

Ripalda: -Cuando decís el Padre nuestro, ¿con quién habláis? Con Dios nuestro Padre.

Astete: -Cuando decís el Padre Nuestro, ¿con quién habláis? Con Dios nuestro Señor.

Otra pregunta común a ambos acerca de la presencia de Dios discrepa profundamente en las respectivas respuestas, más académica la de Ripalda; más cálida la de Astete. Para ceñirse al formulario del padrenuestro, Ripalda dedica más adelante otras preguntas a la presencia de Dios en el cielo:

Ripalda: - ¿Dónde está Dios nuestro Padre? En todo lugar, por esencia, presencia, y potencia.

Astete: $\quad-i$ Dónde está Dios nuestro Señor? Está en todo lugar, especialmente en los cielos y en el Santísimo Sacramento del Altar.

Ripalda: - -Pues ¿Por qué decís que está en los cielos? Porque en ellos se manifiesta más particularmente.

Gabriel Menéndez de Luarca ha anticipado a la explicación detallada del Padrenuestro algunas generalidades sobre la oración. La pregunta sobre las clases o manera de oración, propia de Menéndez de Luarca, ha sido literalmente reproducida por Juan Antonio de la Riva. No ha sucedido lo mismo con las explicaciones detalladas que da sobre la oración mental y vocal:

M. Luarca: - ¿De cuántas maneras es la oración? Mental y vocal.

- ¿Qué cosa es la mental? Es la que se hace ejercitando las potencias del 
alma: acordándonos con la memoria de alguna cosa buena; pensando y discurriendo con el entendimiento sobre ella; y haciendo con la voluntad varios actos, como de dolor de los pecados, o varias. resoluciones, como de confesarnos o mudar de vida.

- ¿Qué cosa es la vocal? Es la que se hace con palabras exteriores; v.gr., la que hacemos cuando rezamos el Padre Nuestro.

De la Riva: - ¿De cuántas maneras es la oración? De dos, mental y vocal.

$-i$ Qué formas hay de orar? Tres: alabando a Dios, dándole gracias y pidiéndole beneficios.

Además Gabriel Menéndez ha tenido presente al corregir a Astete la idea de Ripalda de hablar de las condiciones de la oración, aunque Ripalda se fije en la «piedad», substituida en Menéndez de Luarca por la «atención»:

Ripalda: $\quad-i$ Cuáles son las condiciones de la buena Oración? Piedad, confianza, humildad y perseverancia.

M. Luarca: - ¿Cómo sé ha de orar? Con atención, humildad, confianza y perseverancia.

Otra pregunta original de Gabriel Menéndez de Luarca inquiriendo sobre la presencia de Cristo, en paralelismo con la que hablaba de la presencia de Dios, ha sido reproducido casi con total exactitud por Juan Antonio de la Riva:

M. Luarca: - Y Cristo en cuanto hombre, ¿dónde está? Solamente en el cielo y en el Santísimo Sacramento del Altar.

De la Riva: -Cristo en cuanto hombre, ¿dónde está? En el Cielo, y en el Santísimo Sacramento del Altar.

Antes de entrar en el análisis de cada una de las peticiones del padrenuestro, Jerónimo de Ripalda realiza una clasificación global de ellas y una explicación conjunta. Un gesto semejante no ha sido seguido en sus respectivas intervenciones en el catecismo ni por Astete, ni por Menéndez de Luarca.

Con las naturales similitudes, las explicaciones de cada petición del padrenuestro a cargo de Ripalda y Astete se diferencian hasta el punto de que se puede afirmar que no hay dependencia del uno respecto del otro. Astete resulta más pedagógico en su formulación, pues explica cada petición después de haber recordado cada una separadamente. Ripalda tiene la originalidad de dedicar una pregunta acerca del sentido de pedir con limitación para el presente sin ulteriores preocupaciones para el futuro. La explicación de la petición de perdón ha sido ofrecida en dos preguntas por parte de Ripalda y en una sola por parte de Astete.

En cambio, Juan Antonio de la Riva ha sido influido directamente por Astete a la hora de mostrar el significado de la palabra «amén». Es un detalle que Ripalda no había tratado.

Pero Ripalda tiene la originalidad de mencionar en conjunto otras oraciones de la Escritura, la Iglesia y los Santos, sin descender a más detalles. 
También da el consejo ascético de procurar continuar la oración a pesar de la aparente falta de condiciones para ello.

Como ya hemos indicado, Juan Antonio de la Riva ofrece una clasificación sin precedentes en los redactores anteriores sobre la base de la intención con que se hace la oración: oración de alabanza, acción de gracias y petición.

Ripalda y Astete coinciden literalmente, excepto un detalle del orden de redacción en preguntar por el sentido de la oración a los ángeles y santos:

Ripalda: $\quad-¿$ ¿Hemos de hacer también oración a los Ángeles y a los Santos? Sí, Padre, como a nuestros medianeros.

Astete: $\quad-i$ Hemos de hacer oración también a los Ángeles y a los Santos? Sí, padre, como a nuestros medianeros.

Las explicaciones de ambos sobre los ángeles acusan divergencias en el número de preguntas empleadas y en el acento puesto en ellas. Astete se ocupa expresamente del ángel de la guarda, mientras que Ripalda lo hace de pasada. Pero coinciden en asignar como papel primero de los ángeles la alabanza divina, y en segundo término el cuidado de la Iglesia. Ripalda se fija para ello en el significado etimológico de la palabra «ángel» como mensajero o recadero:

Ripalda: - - - QQué cosa son Ángeles? Espíritus soberanos, que están a Dios alabando.

— ¿De qué le sirven más que de eso? De guardar los hombres, y traer y llevar a Dios recados suyos.

Astete: $\quad-i$ Qué cosa son los ángeles? Son unos espíritus bienaventurados, que están gozando de Dios en el cielo.

- ¿Para qué los crió Dios nuestro Señor? Para que eternamente le alaben y bendigan.

- ¿Y para qué más? Para que, como ministros suyos, gobiernen la Iglesia y guarden los hombres.

- Luego, ¿vos tenéis Ángel que os guarde? Sí, tengo, y cada uno de los hombres tiene el suyo.

Para las explicaciones sobre el Ave María y la Salve, Ripalda y Astete siguen un orden similar (enumeración de las oraciones dichas, origen de cada una, a quién se dirigen, descripción de quién es la Virgen, dónde se encuentra y explicación del sentido de venerar las imágenes). Se puede sospechar que Astete haya tenido a la vista el catecismo de Ripalda, o que ambos dependan de una fuente previa común, pues si no resulta difícil explicar tanta coincidencia en un tratado que por ser menos clásico que el del padrenuestro, se prestaba a una variedad mayor.

Ripalda resulta más completo y exacto que Astete al precisar el origen del Ave María, la presencia de la Virgen en el cielo en cuerpo y alma, al interesarse por las reliquias de los santos, el sentido de la oración a ellos dirigida e incluso los formularios adecuados para ellos. 
Ripalda: $\quad-i$ Quién hizo el Ave María? De la salutación del Ángel, y de Santa Isabel se tomó la parte, primera, y la Iglesia añadió la postrera.

- ¿Adónde está esa gran Señora? En el Cielo en Cuerpo y Alma.

-Y a las Reliquias de los Santos ¿qué reverencia debemos? La que a ellos mismos, que fueron Templos vivos de Dios.

- ¿Qué oración decís a los Santos? Las Letanías, y otras; y también el Padre nuestro, y Ave María.

-Pues cómo: ¿en el Padre nuestro y Ave María no habláis con Dios y su Madre? Sí; mas a Dios pido por medio de los Santos, y a ellos que me sean intercesores.

Astete: $\quad-i$ Quién dijo el Ave María? El Arcángel San Gabriel, cuando vino a saludar a Nuestra Señora la Virgen María.

- ¿Quién es nuestra Señora la Virgen María? Es una Señora llena de virtudes, que es madre de Dios y que está en el cielo.

-Y la que está en el altar, ¿quién es? Es una imagen y semejanza de la que está en el cielo.

- ¿Para qué está alli? Para que por ella nos acordemos de la que está en el cielo y por ser su imagen la hagamos reverencia.

Pues lo mismo habéis de hacer a las imágenes de los demás Santos.

A propósito de las reliquias de los santos, lo que no tuvo en cuenta Astete lo introdujo como modificación su corrector Gabriel Menéndez de Luarca:

Pues lo mismo habéis de hacer a las imágenes de los Santos y a sus reliquias.

Se deduce la influencia de Jerónimo de Ripalda sobre Menéndez de Luarca, quien tenía en cuenta sus aportaciones a la hora de corregir el texto de Astete.

\section{MANDAMIENTOS}

Ni en Astete ni en Ripalda hay una introducción global al conjunto de los mandamientos, excepto la mera frase redaccional de Astete para lo que constituye en su texto la tercera parte:

«Ya hemos visto lo que habéis de creer y orar: veamos cómo sabéis lo que habéis de obrar».

\section{$1{ }^{\circ}$ mandamiento}

El enfoque de Astete y Ripalda para el primer mandamiento es diverso. Los respectivos esquemas sólo tienen un punto en común cuando preguntan qué significa el amor a Dios sobre todas las cosas:

Ripalda: $\quad-¿$ Qué es amar a Dios sobre todas las cosas? Querer antes perderlas que ofenderle. 
Astete: $\quad-¿ Q$ Qué es amarle sobre todas las cosas? Querer antes perderlas todas que ofenderle.

Pero mientras Ripalda desarrolla la explicación del primer mandamiento con arreglo a las virtudes de fe, esperanza y caridad, Astete se ciñe al esquema más simple de contemplar lo que manda y lo que prohíbe.

Menéndez de Luarca recoge algunas de las explicaciones de Ripalda acerca de las virtudes y después de darles una nueva redacción las incorpora al texto de Astete, como algo que está incluido en las prohibiciones del primer mandamiento, pero sin especificar qué virtud resulta lesionada.

Ripalda $\quad-i Q$ Quién peca contra la $\mathrm{Fe}$ ? El que cree cosas supersticiosas, ignora, niega, o duda las necesarias.

- ¿Quién peca contra la Esperanza? El que desconfía de la misericordia de Dios, o locamente presume de ella.

$-i$ Quién peca contra la Caridad? El ingrato a sus beneficios, y a su voluntad, y a la Ley es desobediente.

M. Luarca: - ¿Quién peca contra esto? (la pregunta y parte de la respuesta es de Astete; la aportación de Menéndez de Luarca es:) El que cree alguna cosa contra la fe, o duda de alguno de sus misterios, o ignora los necesarios; el que no hace, cuando está obligado, actos de Fe, esperanza y Caridad, o desconfía de la misericordia de Dios, o recibe indignamente algún Sacramento.

Por su parte, De la Riva añade al catecismo de Ripalda unà pregunta claramente tomada de Gaspar Astete que dice que ama a Dios quien observa sus mandamientos:

Astete: $\quad-i$ Quién ama a Dios? el que guarda sus santos Mandamientos.

De la Riva: - - Quién ama a Dios? El que guarda sus Mandamientos.

Además, la influencia de Gaspar Astete sobre De la Riva se deja sentir al hablar de la superstición, que Ripalda no había mencionado, mientras que De la Riva sí lo hace:

Astete: $\quad-i$ Quién más? (peca) El que cree en agüeros, o usa de hechicerías, o cosas supersticiosas.

De la Riva: - - Quién peca contra Religión? El que adora los Ídolos o Dioses falsos; y los supersticiosos, y sacrílegos que profanan las cosas santas.

- ¿Qué cosa es superstición? Culto vicioso.

Por otro lado, también asume De la Riva la síntesis que Gabriel Menéndez había hecho de la enseñanza de Ripalda sobre la fe, esperanza y caridad, y la reproduce casi con las mismas palabras:

De la Riva: - - ¿Quién peca por omisión contra este Mandamiento? El que no hace cuando debe actos de Fe, Esperanza, Caridad y Religión.

Se trata de un caso claro de cómo al ser De là Riva el último que inter- 
viene en la configuración del catecismo correspondiente, recoge la herencia de sus antecesores.

Pero como Juan Antonio de la Riva no carece totalmente de originalidad, añade al catecismo de Ripalda una aportación tratando expresamente de la virtud de la religión, que añade a las de fe, esperanza y caridad, que Jerónimo de Ripalda había mencionado.

\section{2. ${ }^{\circ}$ mandamiento}

Coinciden exactamente Ripalda y Astete en la pregunta sobre lo que es jurar en vano.

Ripalda: $\quad-i$ Quién se dice jurar en vano? El que jura sin verdad, sin justicia o necesidad.

Astete: $\quad-i$ Quién se dice jurar en vano? El que jura sin verdad, sin justicia o sin necesidad.

Asimismo coinciden los dos en las respuestas al pecado de jurar por las criaturas y el remedio para no jurar en vano, con la particularidad de que la coincidencia se da sólo en las respuestas respectivas, pero no en las preguntas:

Ripalda: $\quad-i Y$ es también pecado jurar por las criaturas en alguna manera de éstas? Sí Padre, porque se jura al Criador en ellas.

-Pues, ¿cómo diremos para no pecar? Sí, o no, como Cristo nos enseña.

Astete: $\quad-i Y$ es pecado jurar en vano por las criaturas? Sí, Padre, porque se jura al criador en ellas.

- ¿Qué remedio hay para no jurar en vano? Acostumbrarse a decir sí o no, como Cristo nos enseña.

Astete dedica pocas preguntas al tema del segundo mandamiento; en cambio, Ripalda lo ha tratado más ampliamente abordando cuestiones como las condiciones del juramento atendiendo a la verdad, la justicia o la necesidad por separado. Gabriel Menéndez de Luarca se ha fijado en las preguntas de Ripalda a la hora de perfeccionar el catecismo de Astete, aunque las ha seguido muy de lejos y les ha proporcionado una redacción propia. Se puede hablar en este caso únicamente de una influencia indirecta.

Con respecto a los votos, Jerónimo de Ripalda se centra en una cuestión que resulta más matizada en la respuesta que Gabriel Menéndez de Luarca ha redactado para el catecismo de Astete, pues señala la obligación de cumplirlos cuando se trata de materia grave:

Ripalda: -Cuanto a los votos, me decid: ¿cuándo es pecado no cumplirlos o dilatarlos? Cuando no hay razón para ello, a juicio de Letrados.

M. Luarca: -Y el que jura o hace voto o promesa de hacer alguna cosa buena, ¿está obligado a cumplirla? Sí, Padre, y el no cumplirla o dilatarla notablemente es pecado mortal siendo la materia grave. 
Además de estas cuestiones sobre los votos, volvemos a constatar la originalidad de Juan Antonio de la Riva adicionando al catecismo de Ripalda tres preguntas más sobre los votos, que sus predecesores habían pasado por alto: Qué es voto, cómo ha de ser mejor que lo contrario a lo prometido y cómo se han de hacer los votos.

La blasfemia ha sido tratada independientemente por Gabriel Menéndez de Luarca y por Juan Antonio de la Riva, añadiendo sendas preguntas a los catecismos por ellos corregidos.

Hay además dos preguntas de Ripalda en extremo interesantes y que no han encontrado acogida por parte de Gastar Astete ni de Menéndez de Luarca, lo que es prueba de que el influjo ejercido por uno de los redactores sobre los demás, no ha condicionado necesariamente su intervención. Se trata de las preguntas que versan sobre la malicia del juramento hecho sin verdad o sin justicia, y de la actitud de arrepentimiento que debe tener quien ha emitido un juramento en esas condiciones:

Ripalda: - ¿Por qué se ofende a Dios tanto en esas dos maneras de juramento? Por ser gran desacato traerle por testigo de cosas falsas, o mal hechas.

-Pues quien ha jurado de hacer algo mal hecho, ¿qué hará? Dolerse de haberlo jurado, y no cumplirlo.

\section{3. ${ }^{\circ}$ mandamiento}

Dentro de la coincidencia natural al tratar de la misma materia, se observa una autonomía mayor por parte de cada uno de los que han intervenido en la redacción. Astete ofrece en conjunto el sentido de oír misa en las fiestas y no trabajar; por su parte, Ripalda trata por separado cada uno de dichos aspectos.

Gabriel Menéndez de Luarca corrige a Astete matizando la clase de pecado que se comete en función de la urgencia y la duración del trabajo realizado en una fiesta; Juan Antonio de la Riva corrige a Ripalda preguntando por el sentido de las fiestas del Señor, de la Virgen y los Santos.

En la práctica, ninguno de los cuatro redactores ha interferido la labor realizada por los demás.

\section{4. ${ }^{\circ}$ mandamiento}

Astete coincide casi totalmente con Ripalda al señalar en qué consiste honrar a los padres, y a quiénes se hace extensiva tal denominación. Se puede pensar en algo más que una coincidencia puesto que de las seis palabras empleadas, cinco son comunes a ambos:

Ripalda: $\quad-i$ Quién se dice con verdad que honra a sus padres? Quien los obedece, socorre y reverencia.

- ¿Quién otros son tenidos por padres demás de los naturales? Los mayores en edad, saber y gobierno. 
Astete: $\quad-i$ Quién honra a los padres? El que los obedece, socorre y reverencia. - ¿Quiénes otros son entendidos por los padres? Los mayores en edad, dignidad y gobierno.

Pero Ripalda y Astete divergen porque la aportación de aquél es mucho mayor en cantidad. Señala en síntesis los deberes de los padres hacia los hijos y los recíprocos entre esposos y entre amos y criados. Todo ello está ausente del escrito de Astete.

Por su estilo más amplio y minucioso, con una fuerte carga moralizante, no parece que las aportaciones de Gabriel Menéndez de Luarca al catecismo de Astete hayan tenido presente lo escrito anteriormente por Jerónimo de Ripalda, aunqué prácticamente aborda los mismos puntos que éste.

Por su lado, Juan Antonio de la Riva adiciona otras preguntas que nada han tenido que ver con las redacciones anteriores. Se centran en el respeto debido a las autoridades civiles así como eclesiásticas, y además recuerda la promesa veterotestamentaria de larga vida para los hijos atentos con sus padres.

\section{5. ${ }^{\circ}$ mandamiento}

La pregunta con que Gaspar Astete pretende explicar el contenido del quinto mandamiento reproduce casi con fidelidad la enseñanza que Ripalda presenta en su catecismo:

Ripalda: -Sobre el quinto Mandamiento os pregunto: ¿qué veda más que el matar? No hacer a nadie mal en hecho, ni en dicho, ni aun en deseo.

Astete: $\quad-¿$ Qué se manda en este mandamiento? No hacer mal a nadie, ni en hecho, ni en dicho, ni aun por deseo.

Además Ripalda incluye una pregunta sobre las posibles infracciones al quinto mandamiento. Tal pregunta es desechada por el moralista Gabriel Menéndez quien especifica minuciosamente los supuestos que constituyen infracción, extendiéndose incluso con gran amplitud a la maldición; finalmente repara en el escándalo, pero lo hace con una explicación confusa que podría dar a entender que el escándalo queda ceñido sólo al caso de algún superior que maldiga ante sus subordinados.

Más exacto resulta en el tema del escándalo Juan Antonio de la Riva quien amplía las posibilidades de escandalizar a los dichos o a los hechos que induzcan a pecado. No termina aquí la aportación propia de De la Riva, pues llena el vacío que habían dejado Ripalda, Astete y Gabriel Menéndez al interesarse por las obligaciones que contrae el que ha injuriado o escandalizado.

\section{6. ${ }^{\circ}$ mandamiento}

También en el sexto mandamiento hay una coincidencia básica en la explicación de Jerónimo de Ripalda y en la paralela de Gaspar Astete, en torno a lo que se manda en el precepto estudiado. Ripalda amplía más que Astete el número de sus preguntas, dedicando unas expresamente a los malos pensamien- 
tos, el debido uso del matrimonio y los medios ascéticos para conseguir la castidad, así como las ocasiones que lo impiden.

Gabriel Menéndez de Luarca emprende otro camino por su cuenta y señala las posibles transgresiones al mandamiento en una enumeración en la que sorprendentemente no alude ni siquiera de pasada al matrimonio.

Juan Antonio de la Riva amplía de su propia cosecha la enumeración de los medios ascéticos que Ripalda comenzara a exponer.

\section{7. ${ }^{\circ}$ mandamiento}

Gaspar Astete se reduce al esquema esencial del contenido de las obligaciones que impone el séptimo mandamiento, aunque no parece aventurado suponer que haya tenido delante las explicaciones de Jerónimo de Ripalda, que también en este caso son más amplias en cantidad que las de Astete.

Ripalda: - $\quad$ Sobre el séptimo Mandamiento os pregunto: ¿Quién le cumple? Quien no toma, ni tiene, ni quiere lo ajeno contra la voluntad de su dueño.

Astete: $\quad-i$ Qué se manda en este mandamiento? No quitar, ni tener, ni querer lo ajeno contra la voluntad de su dueño.

Ripalda se fija además en algunas infracciones que se pueden cometer y en la obligación de restituir, cuestiones ambas que Astete omite.

Gabriel Menéndez de Luarca va a insistir en los mismos puntos en que Ripalda sobrepasa a Astete, pero lo que hace con mucho más rigor en la expresión tratando de buscar una gran exactitud:

Ripalda: $\quad-i$ Quién le quebranta? Quien a otro hace alguna manera de daño injusto, o es causa de que otro lo haga.

-y al que hurtó, o dañó, ¿bastarle ha confesar su pecado? No, si no paga lo que debe, o a lo menos la parte que puede.

$-Y$ el que no puede, ¿qué hará? Procurar como pueda cuanto en sí fuere.

M. Luarca: $-i Y$ quiénes pecan mortalmente contra esto? Los que ejecutan cualesquiera de estas cosas, o de alguna otra manera hacen daño al prójimo en sus bienes en materia grave.

-Y los que en esto hacen daño al prójimo de cualquier manera que sea, ¿quedan con alguna obligación? Quedan con la grave obligación de restituirle y satisfacerle, cuanto antes, todos los daños que le han hecho.

En cambio, Juan Antonio de la Riva va a conservar su originalidad preguntando por cuestiones omitidas por sus antecesores: las obligaciones que tiene todo el que vende algo y las cuestiones más sutiles sobre el monopolio y la usura. 


\section{8. ${ }^{\circ}$ mandamiento}

Así como Astete y Ripalda discrepan en sus respectivas redacciones sobre lo que se debe hacer para cumplir con este mandamiento, sus aportaciones se aproximan entre sí al tratar de lo que le quebranta, aunque Astete incluye el supuesto de juicio temerario que está ausente en Ripalda:

Ripalda: - - QQuién cumple con el octavo Mandamiento? El que no juzga males ajenos ligeramente, ni los dice, ni oye sin fines buenos.

$-i$ Quién le quebranta? Quien infama contra justicia, descubre secreto, o miente.

Astete: $\quad-i$ Qué se manda en este mandamiento? No juzgar ligeramente mal del prójimo, ni decir ni oír sus defectos.

- ¿Quién quebranta este mandamiento? El que contra razón juzga, infama, descubre secreto, o miente.

En cambio, la cuestión propia de Ripalda acerca de si se puede mentir con un fin bueno no ha encontrado eco en el catecismo redactado por Astete.

Gabriel Menéndez de Luarca ha corregido a Astete explicando que es necesario tener un fundamento para juzgar a alguien, y preguntando también por la obligación subsiguiente de restituir la fama lesionada. Juan Antonio de la Riva es influido por Astete en lo que respecta al juicio temerario; y también es influido por Gabriel Menéndez de Luarca en lo relativo al fundamento necesario para emitir un juicio así como en la obligación de restituir la fama:

De la Riva: - $-i$ Qué cosa es juicio temerario? Juzgar mal del prójimo sin motivo ni fundamento para ello.

$-i$ Cuándo el mal juicio será fundado? Cuando en lo mal hecho no cabe disculpa.

—Quién infama, o quita la honra, ¿a qué está obligado? A restituirlá pronto en el modo que pueda, y reparar los daños que se hayan seguido.

Además de las influencias que sobre él pesan y que hemos señalado, Juan Antonio de la Riva es absolutamente original cuando afirma que no resulta suficiente para cumplir con la obligación de restituir la fama con el hecho de la confesión; lo mismo ocurre cuando pregunta por la definición de mentira, por la de murmuración y por la obligación que tiene quien calumnia.

\section{9. ${ }^{\circ}$ y $10 .{ }^{\circ}$ mandamientos}

Resulta significativo que Ripalda y Astete traten conjuntamente los mandamientos nov́eno y décimo. En su exposición, Ripalda resulta más explícito pues pregunta por el sentido directo de los mandamientos, por el exceso que supone la codicia desmesurada y por la razón de ser de un mandamiento específico para ellas. Astete no le sigue sino que únicamente centra su atención en el sentido directo de los mandamientos.

Juan Antonio de la Riva añade al catecismo de Astete por iniciativa pro- 
pia el sentido de complementariedad respecto a los mandamientos sexto y séptimo y el motivo que existe para frenar la voluntad de toda clase de apetencias.

Gabriel Menéndez de Luarca no hace aportación alguna a esta materia.

\section{DE OTROS MANDAMIENTOS}

El tratado sobre otros mandamientos no contenidos en los de la ley de Dios es original de Ripalda en su totalidad. Incluye las obligaciones de la ley natural y las específicas del propio estado $u$ oficio.

Este tratado no ha tenido repercusión en el catecismo redactado por Gaspar Astete: buena prueba de que aunque a veces se adivina una cierta influencia, ella no anula la creatividad propia ni el plan que cada uno de los dos autores se propuso seguir.

Tampoco ha tomado referencia alguna de dicho tratado Gabriel Menéndez de Luarca para incorporarlo al catecismo de Astete en búsqueda del perfeccionamiento del texto. Ni Juan Antonio de la Riva se ha visto en la precisión de matizar alguna cuestión de las escritas por Ripalda.

Llama la atención tal silencio por parte de Astete, Menéndez de Luarca y De la Riva, especialmente por parte de estos dos últimos que tantas cuestiones añaden, en muchas ocasiones totalmente superfluas. No se puede invocar como explicación el que en algún apartado de la exposición de los mandamientos de la ley de Dios estuviera incluida alguna referencia al cumplimiento de las obligaciones del propio estado.

Y si acaso han estimado que no son cuestiones que interesen directamente a los niños - justificando así su omisión en el texto del catecismo- aplicando la misma lógica habría que eliminar no pocas de las preguntas que Menéndez de Luarca y De la Riva adicionaron a los textos por ellos corregidos.

\section{MANDAMIENTOS DE LA IGLESIA}

Los mandamientos de la Iglesia han sido considerados globalmente por Astete en una sola pregunta sobre el sentido total como complemento y explicación de los mandamientos divinos. Dicha pregunta encuentra un cierto paralelismo con la primera que Ripalda consagra al tema:

Ripalda: - ¿Para qué son estos mandamientos de la Iglesia? Para más explicar algunos divinos.

Astete: $\quad-¿$ Para qué son estos mandamientos? Para mejor guardar los divinos.

Ya indicamos al final del comentario sobre las preguntas del credo la similitud de conceptos al hablar de la Iglesia y del papa, y los diversos matices originales de Ripalda y Astete. También es una singularidad el que Astete escogiera aquel momento para hablar de tales cuestiones, mientras que Ripalda 
prefiera hacerlo al comenzar la explicación de los mandamientos de la Iglesia. Por el lugar que cada uno dedica al tema, parece que Astete subraya más el sentido de la Iglesia como misterio de fe, al preferir tratar de ella en el símbolo; y que Ripalda destaca el aspecto jurídico al hacer la presentación de la Iglesia en el encabezamiento de las explicaciones sobre los mandatos positivos emitidos por ella.

\section{1. ${ }^{\circ}$ mandamiento de la Iglesia}

Ripalda centra sus explicaciones en el aspecto sacrificial de la misa, sus fines y sus beneficiarios. Al final se ciñe estrictamente a lo que especifica el primer mandamiento interesándose por las condiciones para cumplir con el precepto, y por quiénes están exentos de oír misa.

Más rigorista, Gabriel Menéndez de Luarca concreta su aportación preguntando por los que están obligados a cumplir con el precepto, por lás condiciones en que han de hacerlo (aunque no se adivina una influencia directa de la pregunta similar propia de Ripalda) y por el pecado que se comete, en una larga y minuciosa serie de supuestos que contravienen el primer precepto.

Por el contrario, en sus correcciones al catecismo de Ripalda, Juan Antonio de la Riva pone el acento en los que de hecho asisten a Misa y se interesa en cómo han de ocuparse en ella a través de la unión con el sacerdote.

\section{2. ${ }^{\circ}$ y $3{ }^{\circ}$ mandamiento de la Iglesia}

Tratados conjuntamente ambos mandamientos, Ripalda tan sólo se preocupa por el mínimo marcado por la ley y la conveniencia de ampliar ese mínimo hacia una vida sacramental más frecuente; remite al juicio que emita el confesor a la hora de intensificar la vida sacramental.

Gabriel Menéndez de Luarca también los trata conjuntamente, pero desde otra perspectiva: se fija en quiénes están obligados a observar estos mandamientos y la clase de infracción que cometen al omitir su cumplimiento. Otra adición de Gabriel Menéndez sobre la conducta a observar al no encontrar confesor en peligro de muerte, recuerda inmediatamente otras dos preguntas anónimas que en el catecismo de Ripalda acompañan las explicaciones de la penitencia.

Por tratarse de unas adiciones anónimas no resulta fácil determinar posibles influencias. Ahora bien, en caso de haberse producido tales influencias, sería tal redactor anónimo el que hubiera propiciado la posterior adición de Gabriel Menéndez de Luarca, ya que las preguntas que introdujo constan al menos en la edición del catecismo de Ripalda fechada en Madrid, 1728, anterior en casi sesenta años a las modificaciones introducidas por Menéndez de Luarca en el texto de Astete. Pero tales preguntas difieren lo suficiente como para poder afirmar que como máximo Gabriel Menéndez las haya tenido presente, pero dando a sus preguntas otra redacción diferente:

Anónimo: -Y si a la hora de la muerte se hallase uno sin Sacerdote que le absuelva, 
¿ha de decir los pecados a los seglares? No; pero es bien delante de ellos dar muestras de dolor y pedir confesión.

-y si el peligro no da lugar, y el doliente se halla en pecado mortal, ¿qué remedio para no condenarse? El remedio es hacer un acto de verdadera contrición y amor de Dios, siquiera con el corazón.

M. Luarca: -Y si uno en peligro de muerte no tiene confesor, ¿qué debe hacer? Un acto de perfecta contrición con propósito de confesarse.

\section{4. ${ }^{\circ}$ mandamiento de la Iglesia}

Jerónimo de Ripalda se limita a exponer en su catecismo en qué consiste el precepto, la hora en que se ha de hacer la comida, la clase de alimentos permitidos, lo que ha de constituir la cena, quiénes están dispensados del ayuno y la conveniencia de ir haciendo una renuncia voluntaria a ciertos alimentos aun sin estar obligado por ley.

Gabriel Menéndez de Luarca no le sigue. Consecuente con su punto de vista, explica quiénes están sujetos a la ley, en qué consiste esencialmente el ayuno, la permisión de la cena y la sanción moral existente contra los transgresores. Tan sólo parece deducirse una influencia cuando escribe acerca de la cena, pues recuerda inevitablemente la expresión que anteriormente empleara Ripalda, quien alude al uso común «entre gentes de buena conciencia», aunque Gabriel Menéndez adiciona el consejo de consultar al confesor:

Ripalda: $\quad-i$ Cuánta debe ser la colación de la noche? Cuanta se usa comúnmente entre gente de buena conciencia.

M. Luarca: $-i Y$ a la noche? Se puede tomar de colación lo que se usa entre gente de buena conciencia, preguntando sobre esto, en caso de duda, a un docto confesor.

Juan Antonio de la Riva se limita a introducir la referencia a la antigua prohibición de mezclar carne y pescado en la misma comida, incluso para los dispensados del ayuno.

Sobre la materia del cuarto mandamiento de la Iglesia, prescindimos de las adiciones posteriores que han procurado actualizar la legislación sobre la materia y que en la mayor parte de los casos versan sobre la abstinencia y sobre el calendario de días en que había que cumplir tales preceptos.

\section{5. ${ }^{\circ}$ mandamiento de la Iglesia}

Del quinto mandamiento de la Iglesia únicamente se ha ocupado Jerónimo de Ripalda, por lo que no hay cuestión sobre coincidencia o influencias. Llama la atención el que Astete no le haya seguido, ni tampoco Gabriel Menéndez ni el resto de los correctores de Astete, dejando así un vacío en sus explicaciones. 


\section{SACRAMENTOS}

Así como Ripalda y Astete habían omitido toda explicación previa a los mandamientos, ahora ambos coinciden en decir lo fundamental que se exige para un adecuado entendimiento de los sacramentos. A pesar de esa coincidencia básica, difieren en las explicaciones que cada uno ofrece.

Ripalda pregunta por el autor de los sacramentos, cosa que no hace Astete. En cambio, la definición que éste ofrece de los sacramentos es teológicamente más exacta que la de Ripalda:

Ripalda: $\quad-i$ Qué cosa son los Sacramentos? Unas espirituales medicinas, que nos sanan y justifican.

Astete: $\quad-i$ Qué cosa son los Sacramentos? Son unas señales exteriores, instituidas por Cristo nuestro Señor, para darnos por ella su gracia y sus virtudes.

Para suplir la poca exactitud de la definición aportada, Ripalda completa su pregunta con otras dos que versan sobre la justificación y sobre las señales externas de los sacramentos:

Ripalda: $\quad-i$ De qué manera nos justifican? Dándonos gracia interior por señales exteriores.

- ¿Cómo pueden darnos gracia por las señales exteriores? Por los méritos de Cristo aplicados en ellas.

Aunque Ripalda menciona expresamente la gracia, no explica aquí en qué consiste, pues lo ha hecho al hablar de los atributos de Dios, en concreto al hablar de Dios salvador. En cambio, Gaspar Astete aprovecha esta ocasión para hablar de la gracia; su definición coincide casi totalmente con la ofrecida por Ripalda:

Ripalda: $\quad-i$ Qué cosa es gracia? Un ser divino, que nos hace hijos de Dios y herederos de su gloria.

Astete: $\quad-i$ Qué cosa es gracia? Es un ser divino que hace al hombre hijo de Dios $\mathrm{y}$ heredero del cielo.

Astete añade además que los sacramentos infunden las virtudes teologales, lo que le da oportunidad para explicar cada una de ellas. Ripalda lo había hecho al comienzo de su catecismo, al ocuparse de las obligaciones del cristiano y las obras con que se sirve a Dios; y lo volverá a hacer en el apartado que dedica más adelante a las virtudes. Sin embargo, resulta diferente el enfoque y la explicación que cada uno da a las virtudes teologales.

Gabriel Menéndez de Luarca ha matizado el catecismo de Astete introduciendo la cuestión del nombre de la gracia («santificante»), su división y la explicación de las gracias actuales.

Bautismo. Al explicar el bautismo difieren Astete y Ripalda: éste se fija 
en lo que da el bautismo (la gracia y las virtudes) y en el pecado que quita; aquél sólo se fija en el segundo aspecto, con un carácter menos positivo; además explica en qué consiste el pecado original.

Es Gabriel Menéndez de Luarca quien introduce los temas del bautismo de urgencia y la manera de llevarlo a cabo. Juan Antonio de la Riva hace lo propio con el texto de Ripalda, añadiendo además la razón que existe para la imposición del nombre de un santo y el sentido de las promesas hechas en el bautismo.

Confirmación. Hay una coincidencia básica en la explicación que ofrecen sobre la confirmación Ripalda y Astete, como complemento de la regeneración bautismal, aunque Ripalda acentúa la consideración espiritualista con que contempla todos los sacramentos.

Gabriel Menéndez de Luarca se fija negativamente en el pecado que comete quien recibe el sacramento sin las debidas condiciones y después señala lo que ha de hacer para recibirlo sin cometer pecado. Enfocándolo desde otro ángulo, Juan Antonio de la Riva es menos rigorista en sus adiciones al catecismo de Ripalda y se fija en el estado de gracia como disposición para recibirlo sin señalar ninguna censura moral al tema. Además se fija en el conocimiento del sacramento que se va a recibir, cuestión que había omitido Gabriel Menéndez en sus correcciones al Astete, ya que no era una cuestión que afectara a la validez del sacramento. Juan Antonio de la Riva tiene una visión más pastoral y más próxima a la vida cristiana.

La aportación de De la Riva se complementa con una pregunta sin precedentes sobre la diferencia entre el bautizado y el confirmado, diferencia semejante - según él- a la que existe entre un niño de pecho y un varón,fuerte y robusto.

Penitencia. Discrepando en el enfoque respecto a la penitencia, pero con una común referencia a la acción del sacramento, Ripalda y Astete emprenden su estudio. Astete habla expresamente de los pecados y en consecuencia ofrece la doble clasificación en mortal y venial. Empieza a explicar los mortales y cómo se perdonan, llegando a la cuestión de las partes de la penitencia y lo que ha de hacer el penitente para el perdón de los pecados mortales; sólo después de esto explica en qué consisten los pecados veniales y cómo se perdonan: se trata de una duplicación del mismo cliché: mortales y su perdón; veniales y su perdón.

Menos pedagógico resulta Ripalda, ya que deja las explicaciones de los pecados para otro tratado posterior, con lo cual todo el tratado de la penitencia arrastra una deficiencia básica. Ripalda hace gravitar su interés en los actos del penitente y explica con un cierto detenimiento cada uno de ellos, constituyendo el hilo conductor de las preguntas que incluye en su catecismo. Los caminos emprendidos por Ripalda y Astete resultan abiertamente distintos, sin que se produzcan mutuas interferencias, ni tan siquiera apenas coincidencias. 
La aportación de Gabriel Menéndez de Luarca al catecismo de Astete está teñida de un tono moralista propio de un canónigo penitenciario. Desciende a la cuestión del momento preciso en que se cumplen las condiciones para recibir la penitencia; además, amplía la cuestión de los actos del penitente con el examen de conciencia y el propósito de la enmienda.

La pregunta dedicada al examen de conciencia es enteramente original de él. Pero en la que señala las dos clases de contrición, hay un calco casi perfecto de la pregunta anónima que se incorporó con anterioridad a Menéndez de Luarca al catecismo de Ripalda: nueva prueba de que Menéndez de Luarca tenía a la vista alguna edición del catecismo de Ripalda al hacer sus modificaciones:

Anónimo: - ¿De cuántas maneras es la contrición? De dos, una perfecta, y otra menos perfecta, que llaman Atrición.

M. Luarca: - ¿De cuántas maneras es la contrición de corazón? Una perfecta y otra menos perfecta que llamamos atrición.

Respecto a la contrición y atrición, Menéndez de Luarca ofrece unas respuestas peculiares que no parece hayan tenido una influencia directa sobre Juan Antonio de la Riva cuando corrigió el catecismo de Ripalda. Una pregunta anónima incorporada al texto de Ripalda sobre las ventajas que trae la contrición respecto a la atrición puede haber tenido algún ascendiente en las preguntas que añade Menéndez de Luarca sobre la misma materia, pero parece poco probable:

Anónimo: $\quad-i$ Qué bienes nos trae esa Contrición por sí sola sin Sacramentos? Que al que verdaderamente la tiene perdona Dios todos los pecados mortales, aunque sean sin número, lo cual no hace la Atrición.

M. Luarca: $-i Y$ por qué? (es mejor la contrición). Porque el de perfecta contrición nace de amor filial, y el de atrición de temor; por el de perfecta contrición antes que uno se confiese se le perdonan los pecados mortales y se pone en gracia de Dios, mas por solo el de atrición no se consiguen estos efectos.

El moralista Gabriel Menéndez quiere precisar también el momento exacto en que se ha de tener el dolor de los pecados. Esta pregunta no ha encontrado correspondencia en las correcciones de De la Riva al catecismo de Ripalda; pero ha pasado en términos muy similares la que Menéndez incluye interrogando si es suficiente el dolor de atrición:

M. Luarca: - Y para confesarse uno bien, ¿basta el dolor de atrición o se requiere el de perfecta contrición? Comúnmente se dice bastar el de atrición; pero mejor y másseguro es llevar el de perfecta contrición, y éste ha de procurar el que se confiesa.

De la Riva: - ¿Bastará la Atrición para recibir la gracia del Sacramento? Lo más seguro es llevar, o a lo menos excitarse a la verdadera contrición. 
La definición de propósito de la enmienda que Gabriel Menéndez de Luarca adiciona al catecismo de Astete tiene un cierto parecido con la que Juan Antonio de la Riva añade al de Ripalda, aunque se diferencian entre sí lo bastante como para no adivinar una influencia directa:

M. Luarca: $-i$ Qué cosa es propósito? Una firme resolución de jamás ofender a Dios gravemente.

De la Riva: $-i$ Qué cosa es propósito de la enmienda? Una firme resolución de no volver a pecar.

Gabriel Menéndez de Luarca describe en qué consiste el manifestar los pecados, así como las condiciones en que se ha de realizar para no incurrir en sacrilegio. Juan Antonio de la Riva no le sigue en esto, puesto que no añade ninguna pregunta específica que complete lo que en su día dijera Ripalda. Añade, por el contrario, otras preguntas que no están directamente ligadas al hecho de manifestar los pecados, sino que podrían haberse tratado como generalidades previas a la confesión.

Dos preguntas de De la Riva tienen un cierto paralelismo con las correspondientes de Astete, en quien podría haberse inspirado: son las relativas a la conducta que ha de seguir quien se encuentra en pecado mortal con una invitación a confesarse, o al menos hacer un acto de arrepentimiento; en este punto Gabriel Menéndez de Luarca había añadido una precisión en el sentido de que no era suficiente un gesto de arrepentimiento, sino en concreto un acto de perfecta contrición. Esto se ha incorporado a la explicación de Juan Antonio de la Riva:

Astete: $\quad-i Y$ es menester siempre que uno cae en pecado mortal confesarse luego para que se le perdone? Bien sería; pero no es necesario.

- ¿Pues que ha de hacer? Tener verdadero dolor de sus pecados, con propósito de enmendarse y confesarse cuando lo manda la Santa Madre Iglesia.

M. Luarca: - ¿Pues qué ha de hacer? Tener verdadero dolor de perfecta contrición de sus pecados, con propósito de enmendarse y confesarse cuando lo manda la Santa Madre Iglesia.

De la Riva: $-i$ Qué debe hacer el que ha caído en pecado mortal? Confesarse para que se le perdone.

- ¿Y para no estar en desgracia de Dios, entretanto, qué remedio? Hacer un acto de perfecta contrición, con propósito de confesión y enmienda.

Sin que se encuentren precedentes en los redactores anteriores, Juan Antonio de la Riva pregunta también por el precepto que se deja sin cumplir al permanecer en estado de pecado mortal, el remedio para las malas confesiones y las normas para la adecuada elección de confesor. En todo ello resulta enteramente original. Sobre la conducta a seguir cuando sólo se tienen pecados ve- 
niales hay un precedente en Gabriel Menéndez de Luarca que puede haber influido ligeramente en Juan Antonio de la Riva:

M. Luarca: -Y el que después de la última confesión tiene sólo veniales, ¿qué le será conveniente hacer para asegurar el dolor y el propósito? Confesar también, aunque se confiese de éstos, algún pecado mortal de la vida pasada.

De la Riva: - ¿Qué hará para asegurar el dolor el que sólo lleva veniales? Decir, si tuviere, algún mortal de las confesiones anteriores.

La satisfacción o cumplimiento de la penitencia impuesta había sido descrita por Ripalda; en cambio, aunque Astete la menciona expresamente, no dedica a ella ninguna pregunta. Gabriel Menéndez de Luarca se ocupa de llenar el vacío y su descripción se diferencia de la de Ripalda hasta el punto de no dejar adivinar un influjo real. Ripalda había preguntado además por la suficiencia de los padecimientos de Cristo, pero no encontró eco ni en Astete, ni en Menéndez de Luarca. Éste se ocupa de urgir la necesidad de la penitencia bajo la amenaza de pecado mortal y pregunta también por la eficacia de las obras buenas para merecer ante Dios. Las preguntas que sobre este tema adiciona Juan Antonio de la Riva al catecismo de Ripalda emprenden otra dirección distinguiendo las clases de penitencia que existen, satisfactoria y medicinal, con una sucinta explicación de cada una.

Además Gabriel Menéndez de Luarca aprovecha la oportunidad que le brinda la satisfacción penitencial para mencionar las indulgencias: qué son, cómo se han de obtener y su aplicación a quienes están en el Purgatorio. Se despega de esta forma de la influencia directa de Ripalda, que había reservado para las indulgencias un apartado distinto, a continuación de los sacramentos. El contenido de las preguntas de Gabriel Menéndez sobre las indulgencias guarda una ligera referencia a las similares de Ripalda; la que versa sobre la aplicación de las indulgencias a quienes están en el Purgatorio es estrictamente original de Menéndez de Luarca. De la Riva añade sobre esta materia de las indulgencias una serie de preguntas propias sobre su finalidad, la indulgencia plenaria y el jubileo, enteramente singulares.

Astete trata a continuación del pecado venial y cómo se perdona. Se distingue de Ripalda en cuanto a las expresiones empleadas; y respecto a la enumeración de obras que perdonan los pecados veniales, hay diferencia entre ambos en la formulación y en el orden; con todo, el contenido de las obras a realizar es el mismo, lo que parece remitir a una fuente común, a un pensamiento difundido en su época y recogido por cada uno de ellos a su manera:

Ripalda: $\quad-E l$ pecado venial se perdona por nueve cosas: primera, por oír Misa. segunda, por comulgar tercera, por oír la palabra de Dios cuarta, por bendición episcopal quinta por el Pater noster 
sexta, por la confesión general séptima, por agua bendita octava por pan bendito nona, por golpes de pecho.

Astete: $\quad-i$ Por cuántas cosas se le perdona? Por nueve

- ¿Cuáles son? La primera, por oír Misa.

la segunda, por comulgar

la tercera, por decir la Confesión general

la cuarta, por bendición episcopal

la quinta, por agua bendita

la sexta, por pan bendito

la séptima, por decir el Pater noster

la octava, por oír sermón

la novena, por golpes de pecho pidiendo a Dios perdón.

Comunión. Respecto al sacramento de la comunión no da la sensación de que haya mutuas influencias entre Ripalda y Astete, especialmente por la breve extensión que Astete dedica a la materia. Es distinta la descripción del sacramento y tampoco existe coincidencia al hablar de la presencia de Cristo en la eucaristía.

La influencia se aprecia en la afirmación de Ripalda de que en la eucaristía no hay pan y vino, sino sólo sus accidentes; dicha pregunta, retocada además por algún corrector anónimo, ha determinado una muy similar de Gabriel Menéndez de Luarca incorporada al texto de Astete:

Ripalda: $\quad-i$ Luego no hay en el Sacramento substancia de pan y vino? No, sino los accidentes, olor, color, y sabor, etc.

M. Luarca: -Y después de la consagración, ¿hay en la hostia pan o en el cáliz vino? No, Padre, sino los accidentes de pan y vino, como olor, color, sabor, etc.

No ha ocurrido lo mismo con otras preguntas de Ripalda sobre la transmutación del pan y del vino, sobre el poder consecratorio de los sacerdotes y sobre la razón de que los seglares comulguen con una sola especie: tales preguntas originales de Ripalda no han encontrado eco en ningún otro de los redactores que han intervenido con posterioridad a él en la confección de los textos de catecismo.

La pregunta de Ripalda sobre las disposiciones para comulgar no influye decisivamente en las que Gabriel Menéndez de Luarca dedica al mismo tema en el catecismo de Astete. Ripalda, muy esquemático, presenta la doctrina usual sobre la materia; Gabriel Menéndez toma pie en la indicación de Astete de comulgar «dignamente» y explica el significado y el motivo de tal afirmación; además contempla las disposiciones por parte del cuerpo referidas al ayuno eucarístico; y por separado las del alma, contemplando dos supuestos: el de quien ha cometido pecado mortal y el de quien se acuerda de alguno después de haberse confesado: sale a la superficie el moralista que era Gabriel Menéndez de Luarca. 
Hay además otras tres preguntas de Ripalda que no han influido sobre Astete ni han pasado indirectamente a su catecismo a través de Gabriel Menéndez: son las que se refieren a lo que hay que hacer antes y después de comulgar y los beneficios que se siguen para el que comulga.

Menéndez de Luarca ha añadido además otras preguntas peculiares. Dos de ellas encuentran su paralelismo con las que Juan Antonio de la Riva añade al catecismo de Ripalda: las que se refieren al contenido real en la hostia y en el cáliz después de la consagración. Es difícil precisar si se trata de una mera coincidencia, o si Menéndez de Luarca ha arrastrado a Juan Antonio de la Riva en su redacción:

M. Luarca: -Según eso, ¿quién está en la hostia después de la consagración? El cuerpo de Jesucristo, juntamente con su sangre, alma y divinidad.

- ¿Y en el cáliz? La sangre de Jesucristo, juntamente con su cuerpo, alma y divinidad.

De la Riva: - ¿Qué hay en la Hostia consagrada? Cuerpo y Sangre, Alma y Divinidad de nuestro Señor Jesucristo.

- ¿Y en el Cáliz? Sangre y Cuerpo, Alma y Divinidad de nuestro Señor Jesucristo.

Otras dos preguntas propias de Gabriel Menéndez versan sobre la presencia de Cristo entero en las especies sacramentales, aun en el caso de tener que dividirlas. Además el Gabriel Menéndez moralista afirma que se comete un sacrilegio si se comulga sin las debidas disposiciones y acompaña una serie de consejos para recibir la comunión con provecho.

Todas las influencias anteriores no privan a De la Riva de originalidad, pues encuentra ocasión para introducir unas preguntas propias. Una versa sobre el significado de la palabra "comunión» como mutua unión entre los creyentes a la vez que unión con Cristo. Otra contiene un exceso de puritanismo al preguntar si tiene que confesarse (se supone que en orden a la comunión) quien ya está en gracia. Ninguno de sus predecesores se había fijado en las condiciones de reverencia, devoción y humildad para la comunión. Además otras dos preguntas sobre la comunión frecuente y las disposiciones de pureza para realizarla obligan a pensar que Juan Antonio de la Riva está ligeramente sensibilizado por el jansenismo que pretende combatir.

Unción de enfermos. Ripalda y Astete dan su versión no coincidente sobre lo que entienden por el sacramento de la unción de enfermos; respecto a los efectos del sacramento, resulta más completa la respuesta de Astete que la de Ripalda, que tiene que ser adicionada por Juan Antonio de la Riva para exponer todos los efectos del sacramento:

Ripalda: $\quad-i$ Qué bienes causa? Limpia las reliquias del pecado, que por ignorancia, o negligencia suelen quedarnos.

De la Riva: - ¿Y qué más obra este Sacramento? Da esfuerzo al alma contra las tentaciones del demonio, y salud al cuerpo; si le conviene. 
Astete: $\quad-i$ ¿Para qué es el Sacramento de la Extremaunción? Para tres cosas. - ¿Cuáles son? La primera para quitar los rastros y reliquias de la mala vida pasada.

La segunda para dar esfuerzo al alma contra las tentaciones del Demonio.

La tercera para dar salud al cuerpo, si le conviene.

Se deja ver claramente incluso en la redacción empleada por Juan Antonio de la Riva el ascendiente que sobre él ha ejercido la redacción previa que escribió Astete.

Ripalda ha ofrecido además una pregunta que quiere explicar el sentido de disponer de un sacramento especial para los momentos finales de la vida; dicha pregunta no ha tenido eco en el catecismo de Astete.

Como moralista que es, Gabriel Menéndez de Luarca se interesa por la obligación que tienen los enfermos de recibirlo, así como las condiciones para hacerlo. En cambio, Juan Antonio de la Riva no le sigue con exactitud, sino que se preocupa con un carácter más pastoral en insistir en que los enfermos lo reciban a tiempo, cuando aún tienen sentido. Además, De la Riva se había centrado en explicar el nombre de «extremaunción» y la adición ya mencionada de completar los efectos del sacramento que Ripalda había omitido.

Cada uno de los principales redactores del catecismo ha intervenido con independencia de las demás excepto la influencia que hemos señalado de Astete sobre De la Riva.

Orden. Aunque Astete y Ripalda pretenden explicar el sentido del sacramento, sus explicaciones tienen un enfoque diferente y no se da dependencia de uno respecto a otro.

Gabriel Menéndez de Luarca se fija en el respeto que hay que tener a quienes han recibido el sacramento del orden. Mientras tanto, Juan Antonio de la Riva explica el nombre dado al sacramento y lo que han de hacer quienes pretenden recibirlo.

Matrimonio. También son independientes las explicaciones escuetas de Ripalda y Astete respecto al matrimonio.

Siguiendo su propio estilo, Gabriel Menéndez apunta las condiciones necesarias para recibir lícitamente el matrimonio y lo que se ha de hacer cuando faltan esas condiciones. Juan Antonio de la Riva resulta más exacto que Gabriel Menéndez en una pregunta similar:

M. Luarca: -Y los que no se hallan en gracia de Dios, ¿cómo se han de disponer para recibirlo? Confesándose.

De la Riva: $-i$ Con qué disposición debe recibirse? Con reverencia, buena intención, y en estado de gracia.

Además De la Riva se interesa por lo que deben saber los cristianos que desean casarse y por la conveniencia de que los hijos consulten a sus padres (o los que hacen sus veces) antes de contraer matrimonio. 


\section{OBRAS DE MISERICORDIA}

Después del tratado de las indulgencias que hemos visto a propósito de la penitencia, Jerónimo de Ripalda aborda la cuestión de las obras de misericordia. En cuanto al momento de tratarlas difiere de Gaspar Astete, el cual lo hace al término de los mandamientos ( $3 .^{\circ}$ parte en que divide su catecismo). La primera pregunta de Ripalda explicando que las obras mencionadas se llaman «de misericordia» porque no se deben en estricta justicia está repetida con total exactitud en el catecismo de Astete:

Ripalda: $\quad-¿$ Por qué se llaman de Misericordia? Porque no se deben de Justicia. Astete: $\quad-i$ Por qué se llaman de misericordia? Porque no se deben de justicia.

La siguiente pregunta de Ripalda sobre las ocasiones en que constituye una obligación llevar a la práctica las obras de misericordia se encuentra en el catecismo de Astete con una gran similitud, variando el orden y consiguientemente la redacción:

Ripalda: $\quad-i$ Cuándo obligan de precepto? En necesidades graves a juicio de discretos.

Astete: $\quad-i$ Cuándo obliga de precepto? En necesidades que, a juicio de hombres discretos, sean graves.

No ocurre lo mismo con las preguntas siguientes de Ripalda, interrogando sobre cuál de ellas es más meritorio y cuál urge más en caso de necesidad. Tales preguntas no tienen correspondencia en el catecismo de Astete.

Gabriel Menéndez de Luarca vuelve su atención a contemplar el provecho que se sigue para el que las realiza, contando con el supuesto estado de gracia, pues en caso contrario el provecho que reportan a quien las lleva a cabo es mínimo. Se trata de unas sutilezas totalmente debidas al moralista segoviano y que reflejan a la perfección sus centros de interés a la hora de perfeccionar el catecismo de Astete.

\section{ENEMIGOS DEL ALMA}

Acerca de ellos, Astete se ha limitado a enumerarlos y preguntar cómo se huye de cada uno de ellos. Ripalda hace una exposición mucho más amplia y prolija con infinidad de detalles. A pesar de ello, sólo se ocupa de la cuestión de cómo huir del mundo, y no hace lo propio con el demonio y la carne. Juan Antonio de la Riva suple esta deficiencia con unas expresiones que parecen haber sido tomadas directamente de las de Astete, aunque hayan sido reelaboradas con otra redacción:

Astete: $\quad-i$ Cómo se huye del demonio? Con oración y humildad.

- ¿Cómo se huye de la carne? Éste se vence y huye con asperezas, dis- 
ciplinas y ayunos; éste es el mayor enemigo, porque a la carne no la podemos echar de nosotros; al mundo y al demonio, sí.

De la Riva: - ¿Cómo se vence al Demonio? Con Oración, humildad, y actos de virtudes contrarias a lo que sugiere y propone.

- ¿Cómo se vence la carne? Con asperezas y ayunos.

Gabriel Menéndez de Luarca se ha limitado a completar el texto de Astete definiendo cada uno de los tres enemigos del alma.

\section{PECADOS}

Ya señalamos hablando de la penitencia la mayor oportunidad pedagógica de Astete al tratar entonces de los pecados; por el contrario, Ripalda se reserva para un tratado posterior.

Otra diferencia perceptible es que Astete, vinculándolos al perdón sacramental, habla sólo de pecados mortales y veniales, mientras que Ripalda incluye además el pecado original pues el que incluye en su catecismo es un tratado sobre toda clase de pecados.

Existe un cierto paralelismo en la definición de pecado mortal, con expresiones muy similares que hacen pensar en una influencia de Ripalda sobre Astete:

Ripalda: $\quad-¿$ Qué cosa es pecado mortal? Pensar, decir, hacer o faltar en algo contra la Ley de Dios en materia grave.

Astete: $\quad-i$ Qué es pecado mortal? Es decir, hacer, pensar o desear algo contra la ley de Dios en materia grave.

No sucede lo mismo con respecto al pecado venial, donde es mayor la divergencia entre ambos:

Ripalda: $\quad-¿ Q$ Qué cosa es pecado venial? El que no mata al alma, pero la enferma. Astete: $\quad-i$ Qué cosa es pecado venial? Es una disposición para el pecado mortal.

En cambio vuelve a haber una aproximación cuando se trata de explicar el por qué del nombre de pecado venial y las nueve cosas por las que se perdona:

Ripalda: $\quad-i$ Por qué se llama pecado venial? Porque fácilmente se comete, y perdona.

Astete: $\quad-¿$ Por qué se llama venial? Porque ligeramente cae el hombre en él y fácilmente se le perdona.

Como el apartado que Ripalda dedica a los pecados es relativamente amplio, hay un buen número de preguntas originales que no han tenido reflejo en el catecismo de Astete.

Juan Antonio de la Riva añade a Ripalda algunas cuestiones. Una en par- 
ticular que explica el concepto de «mortal» aplicado al pecado, está calcada con toda exactitud de la pregunta correspondiente de Astete:

Astete: $\quad-i$ ¿Por qué se llama mortal? Porque mata el alma del que lo hace.

De la Riva: - ¿Por qué se llama mortal? Porque mata el alma del que le hace.

Además otras preguntas son propias de De la Riva: la definición general de pecado, la mayor felicidad o desdicha del hombre (carecer o tener pecado) y el castigo que merece el pecado venial.

\section{PECADOS CAPITALES}

Además de la enumeración de los pecados capitales, Astete y Ripalda lo acompañaba de una serie de explicaciones. Hay una diferencia primera que salta a la vista. Astete sólo explica en qué consiste cada pecado capital, y después de haber terminado la exposición se limita a enumerar las virtudes contrarias a los pecados capitales, pero sin explicación alguna. No sigue en ello a Ripalda, que adjunta a cada pecado capital la virtud contraria, explicando los dos. En este punto, Ripalda resulta más pedagógico que Astete.

Se aprecia diversidad de planteamientos. Pero las coincidencias de algunas explicaciones así como las preguntas introductorias (aclaración de la palabra «capital», analizar su malicia y en qué ocasiones son contra la caridad) obliga a pensar en una fuente común en la que ambos se han inspirado, a no ser que Astete haya tenido a la vista a Ripalda, pero sin copiarle exactamente. Se impone más la sospecha de una fuente común, ya que las convergencias que se dan no son totalmente coincidentes y se observan unas ligeras diferencias no sólo de estilo, sino también de enfoque en los temas abordados.

Ripalda: - - ¿Aquestos siete pecados, por qué se llaman capitales? Porque son cabezas de otros muchos.

- ¿Son pecados mortales las soberbias y avaricias? No todas, sino sólo las que son contra la caridad de Dios, o del prójimo.

${ }_{-}$¿Cuándo son contra la caridad? Cuando se quiebra por ellas algún Mandamiento de Dios, o de la Iglesia.

Astete: - ¿Por qué llamáis pecados capitales a los siete, que comúnmente se llaman mortales? Llámanse capitales, porque son cabeza, y como fuentes y raíces de otros vicios que de ellos nacen; y llamarse mortales no les cuadra tan bien, pues muchas veces no son más que veniales.

- ¿Cuándo son mortales? Cuando son contra la caridad de Dios y del prójimo.

- ¿Cuándo son contra la caridad? Cuando por ellos se quebranta algún mandamiento de Dios o de la Iglesia en cosa grave. 
13. VIRTUDES

Todo el tratado es peculiar de Ripalda, excepto cuatro preguntas adicionadas por Juan Antonio de la Riva. Este tratado no ha tenido ninguna resonancia en el catecismo de Astete, quien se limita a hacer la enumeración de las virtudes. Tampoco ha sido desarrollado por Gabriel Menéndez de Luarca.

Únicamente se da una cierta coincidencia (derivada de abordar la misma materia) en las definiciones que Ripalda y Astete dan de la fe, esperanza y caridad, que como vimos, han sido estudiadas por Astete en otro lugar.

\section{POTENCIAS DEL ALMA}

Hay una aproximación que es más que una coincidencia entre los catecismos de Astete y Ripalda. Además de enumerar las tres potencias del alma clásicas, coinciden en preguntar para qué nos dio Dios cada una de ellas; también coinciden en la explicación respectiva hasta el punto de que las respuestas de Astete constituyen casi un calco de las de Ripalda. Hay un cambio de orden y alguna modificación en las palabras empleadas, lo que no desfigura la gran proximidad existente:

Ripalda: - ¿Para qué nos dio Dios el entendimiento? Para que le conozcamos, y pensemos en cosas suyas.

- ¿Para qué la memoria? Para que nos acordemos de su Ley, y beneficios.

- ¿Para qué la voluntad, y libre albedrío? Para que le amemos, y hagamos con merecimiento la suya.

Astete: $\quad-i$ Para qué nos dio Dios la memoria? Para acordarnos de Él y de sus beneficios.

- ¿Para qué nos dio Dios el entendimiento? Para conocer a Dios Nuestro Señor y pensar en Él.

- ¿Para qué nos dio la voluntad? Para que le amemos como a suma bondad y al prójimo por Él.

Como se trata de las potencias del alma, Gabriel Menéndez de Luarca añade al catecismo de Astete una pregunta que aclare lo que es el alma humana. Juan Antonio de la Riva ha tenido a la vista la explicación de Gabriel Menéndez de Luarca a la hora de introducir semejante modificación en el catecismo de Ripalda:

M. Luarca: $\quad-i Y$ qué cosa es nuestra alma, cuyas son estas potencias? Es un espíritu inmortal creado por Dios de la nada, a su imagen y semejanza.

De la Riva: - ¿Qué cosa es el Alma racional? Un espíritu inmortal, criado por Dios a su imagen, y semejanza. 


\section{SENTIDOS CORPORALES}

Ripalda los enumera en su catecismo. Además los acompaña de una pregunta sobre la finalidad de los sentidos y los miembros recibidos de Dios. La misma enumeración e idéntica pregunta ligeramente retocada está presente en el catecismo de Astete, lo que hace pensar en un influjo directo:

Ripalda: - ¿Para qué nos dio Dios los sentidos, y todos los demás miembros? Para que con todos le sirvamos en todas las cosas.

Astete: - ¿Para qué nos dio Dios los sentidos y todos los demás miembros? Para que con ellos le sirviéramos en todas las cosas.

\section{DONES Y FRUTOS DEL ESPÍRITU SANTO}

En ambos casos Astete se limita a ofrecer la correspondiente enumeración sin ninguna pregunta aclaratoria; por lo tanto no hay lugar a hablar de transvases o influencias procedentes del catecismo de Ripalda. Únicamente cabe remitir a la lectura crítica del texto de Ripalda distinguiendo las preguntas suyas y las añadidas por Juan Antonio de la Riva.

Quizá sea éste el momento de subrayar una diferencia entre ambos catecismos, pues mientras Astete no considera necesaria ninguna pregunta sobre los dones y frutos del Espíritu Santo, Ripalda sí incluye explicaciones sobre los primeros, aunque no sobre los segundos, a cargo de Juan Antonio de la Riva.

\section{BIENAVENTURANZAS}

El mimetismo es prácticamente total en las preguntas de Astete respecto a las de Ripalda, de forma que a excepción de unos pocos detalles se reproducen con exactitud las mismas palabras.

Una extraña pregunta del catecismo de Astete centra nuestra atención. Al terminar la enumeración de las bienaventuranzas pregunta: «¿Qué hemos dicho ahora?». Una pregunta semejante es muy usual en el catecismo de Ripalda en la edición que reproduce el texto de 1591: pone un formulario y antes de explicarlo con preguntas y respuestas hace un puente preguntando: "¿Qué hemos dicho agora?» (sic). Al desplazarse en ediciones posteriores los formularios y oraciones al comienzo del catecismo, dichas preguntas perdieron sentido y terminaron por desaparecer.

Pero en el texto de Astete nos ha quedado aquí un testigo de que en su redacción primera quizá haya seguido el mismo esquema que Ripalda, intercalando los formularios en el texto. Por lo menos así ha ocurrido con las bienaventuranzas. Y no sería demasiado arriesgado suponer lo mismo en el resto 
del catecismo. En las ediciones usuales del catecismo de Ripalda, también las bienaventuranzas se han visto desplazadas al comienzo del catecismo y la pregunta que nos ocupa ha desaparecido. En cambio se encuentra en el texto reproducido de 1591 a continuación de las bienaventuranzas y antes de su correspondiente explicación.

En el texto de Astete se ha conservado lo que suponemos el orden primitivo. Ello nos lleva a pensar que también el orden primitivo de todo el catecismo de Astete era otro, y que los formularios, oraciones y enumeraciones no estaban colocados al principio del catecismo, sino que iban armónicamente integrados dentro del texto. $\mathrm{O}$ que en las bienaventuranzas dependa de la fuente común preexistente.

En el catecismo de Ripalda ha añadido posteriormente Juan Antonio de la Riva unas preguntas sobre las relaciones existentes entre las bienaventuranzas, los dones del Espíritu Santo, sus frutos y las virtudes. Tales preguntas no han tenido precedente ni en Astete ni en Gabriel Menéndez de Luarca.

\section{NOVÍSIMOS}

Es el último tratado presente en el catecismo de Astete, introducido íntegramente por Gabriel Menéndez de Luarca. No ha tenido resonancia en el catecismo de Ripalda, a excepción de la enumeración de los novísimos colocada al comienzo del catecismo. Juan Antonio de la Riva no indica en la edición de Murcia, 1800 anotada por él que sea obra suya el haber introducido allí tal enumeración. En la edición de Madrid, 1783 ya encontramos los novísimos al comienzo del catecismo, lo que nos indica que la enumeración se había incorporado al texto de Ripalda antes de las modificaciones de Juan Antonio de la Riva.

Lo cierto es que Ripalda no los incluyó en el original salido de sus manos.

\section{E P Í L O G O}

De todo lo anteriormente expuesto se desprende que ni siquiera resulta válido remitir a la lectura indiscriminada de los catecismos de Ripalda y Astete tal como nos han sido transmitidos. La carga de aluvión que han ido recibiendo cada uno de ellos con el paso del tiempo ha transformado totalmente lo que eran originariamente, por lo cual su lectura tiene que estar matizada de una gran prudencia y de un conocimiento cierto de autenticidad literaria de cada una de sus partes.

Los dos escritos originales brotados de las plumas respectivas de Jerónimo de Ripalda y de Gaspar Astete han soportado tal violencia que se encuentran desmembrados por la introducción de cuñas, la adición de preguntas o de tratados enteros, la supresión de algunas preguntas o la alteración de no pocas respuestas. 
Los dos principales correctores, Juan Antonio de la Riva y Gabriel Menéndez de Luarca procedieron con toda honradez, distinguiendo lo que era aportación suya del resto del texto al que pretendían respectivamente completar. Leer por separado la parte correspondiente a Ripalda, De la Riva, Astete y Menéndez de Luarca da otra dimensión al conocimiento del catecismo. Hemos tratado de llamar la atención hacia esta lectura hecha con sentido crítico y distinguiendo la paternidad correspondiente de cada frase.

Además, hemos tratado de exponer que en la composición de sus respectivas intervenciones, cada uno de los redactores tuvo a la vista algunos aspectos que habían escrito quienes les precedieron. Se descubren de esta forma unas influencias que en unos casos son patentes y en otros resultan menos claras, pero que permiten concluir que cada uno de ellos consultó lo escrito por los demás, en un afán sincero de mejorar y perfeccionar la exposición de la doctrina cristiana.

Quedan, sin duda, algunos problemas por resolver. Especialmente, la localización de la fuente común de la que presumiblemente dependen Ripalda y Astete. Tendrá que ser objeto de otro trabajo distinto.

Con el presente trabajo creemos haber prestado un servicio a todos los sinceros estudiosos de la catequesis, para descubrir los ocultos derroteros por donde habían discurrido dos de los más célebres catecismos españoles.

Ofrecemos en forma de cuadros sinópticos las respectivas lecturas críticas de los catecismos de Ripalda y Astete. A la vez los acompañamos con otros cuadros que reflejan las influencias ejercidas de unos redactores a otros.

Con ello pensamos haber puesto en entredicho la ' nendación, no exenta de nostalgia, de emplear estos catecismos para la aci..... educación de la fe, como si fueran los únicos instrumentos válidos. No se puede perder de vista que el respectivo núcleo primitivo de los catecismos de Ripalda y Astete siguen la línea de los textos postridentinos y no entroncan con la mejor corriente catequética del siglo XVI, inspirada en un sano humanismo y con notables representantes. El lastre añadido en el siglo XVIII ha terminado por desfigurar totalmente aquellos catecismos, aun con un legítimo afán de completarlos y perfeccionarlos.

Desde entonces ha habido un concilio Vaticano I, que sucintamente ha quedado reflejado en los catecismos. También ha existido - y muy reciente, por cierto- un concilio Vaticano II, con la sana intención de actualizar la imagen pública de la Iglesia y del mensaje de salvación que ha de anunciar a creyentes y no creyentes. Entre los primeros están los niños a quines se dirigen los más recientes catecismos. En ellos se ha querido recoger el latido de nuevas inquietudes, exponiendo la vieja enseñanza de la Iglesia con renovado vigor.

Recurrir a unos textos de hace casi cuatro siglos no parece que sea la mejor solución, por muchas cualidades que encierren. Pero desde luego se falta a la verdad histórica queriendo hacer pasar por original de Ripalda y Astete lo que ni siquiera soñaron en escribir. Ante todo hace falta conocimiento y honradez. 
CLASIFICACIÓN DE LAS PREGUNTAS DEL CATECISMO DE ASTETE

\begin{tabular}{|c|c|c|c|c|c|c|c|}
\hline \multirow{2}{*}{$\begin{array}{l}\text { Astete-Llorente } \\
\text { Valladolid, } 1957\end{array}$} & \multicolumn{6}{|c|}{ N. ${ }^{\circ}$ preguntas } & \multirow{2}{*}{ Adiciones } \\
\hline & Total & Astete & Menénde & S. y Forés & Llorente & Otros & \\
\hline Introducción Urrutia & & & & & $x$ & & \\
\hline $\begin{array}{l}\text { A. Introduc. Doc. Cristiana } \\
\text { Todo fiel cristiano } \\
\text { Credo } \\
\text { Artículos de la fe } \\
\text { Padrenuestro } \\
\text { Ave María } \\
\text { Gloria } \\
\text { Salve } \\
\text { Mandamientos de Dios }\end{array}$ & : & $\begin{array}{l}\mathbf{x} \\
\mathbf{x} \\
\mathbf{x} \\
\mathrm{x} \\
\mathrm{x} \\
\mathrm{x} \\
\mathrm{x} \\
\mathrm{x}\end{array}$ & & & $\mathbf{x}$ & & \\
\hline B. Declaración Doc. Cristiana & 21 & 21 & & & & & \\
\hline C. Division Doc. Cristiana & 6 & 6 & & & & & \\
\hline D. 1. ${ }^{a}$ parte Doc. Cristiana & 64 & 51 & 12 & & & 1 & 3: Sanz y Forés \\
\hline E. 2. ${ }^{a}$ parte Doc. Cristiana & 42 & 37 & 5 & & & & 2: Sanz y Forés \\
\hline $\begin{array}{r}\text { F. 3. parte Doc. Cristiana } \\
\text { Mandamientos Dios } 1 .^{\circ} \\
2 .^{\circ} \\
30^{\circ} \\
4 .^{\circ} \\
50^{\circ} \\
60^{\circ} \\
70^{\circ} \\
8 .^{\circ} \\
90^{\circ} \\
10 .^{\circ}\end{array}$ & $\begin{array}{r}6 \\
13 \\
3 \\
7 \\
8 \\
3 \\
4 \\
4 \\
3\end{array}$ & $\begin{array}{l}6 \\
4 \\
2 \\
3 \\
2 \\
2 \\
2 \\
3 \\
1\end{array}$ & $\begin{array}{l}9 \\
1 \\
4 \\
6 \\
1 \\
2 \\
1\end{array}$ & & & $\begin{array}{l}1 \\
1\end{array}$ & 1: Llorente \\
\hline $\begin{array}{r}\text { Mandamientos Iglesia } \\
1 .^{\circ} \\
2 .^{\circ}-3 .^{\circ} \\
4 .^{\circ} \\
5 .^{\circ} \\
\end{array}$ & $\begin{array}{r}1 \\
3 \\
3 \\
16 \\
\end{array}$ & $=$ & $\begin{array}{r}3 \\
3 \\
5 \\
-\end{array}$ & $\begin{array}{r}7 \\
- \\
\end{array}$ & $\begin{array}{r}4 \\
- \\
\end{array}$ & - & 3: Llorente \\
\hline Obras Misericordia & $\ddot{4}$ & 2 & 2 & & & & \\
\hline $\begin{array}{l}\text { G. } .^{\circ} \text { parte Doc. Cristiana } \\
\text { Sacramentos en general } \\
\text { Bautismo } \\
\text { Confirmación } \\
\text { Penitencia } \\
\text { Comunión } \\
\text { Extremaunción } \\
\text { Orden } \\
\text { Matrimonio } \\
\end{array}$ & $\begin{array}{r}10 \\
4 \\
3 \\
36 \\
14 \\
4 \\
2 \\
3\end{array}$ & $\begin{array}{r}7 \\
2 \\
1 \\
11^{*} \\
2 \\
2 \\
1 \\
1 \\
\end{array}$ & $\begin{array}{r}3 \\
2 \\
2 \\
25 \\
12 \\
2 \\
1 \\
2 \\
\end{array}$ & & & & $\begin{array}{l}\text { 1: Llorente } \\
\text { 1: Llorente } \\
\text { 1: Sanz; } 1: \text { Llorente } \\
\text { 2: Llorente }\end{array}$ \\
\hline $\begin{array}{l}\text { H. Pecados capitales } \\
\text { Virtudes contrarias } \\
\text { Enemigos del alma } \\
\text { Virtudes teologales } \\
\text { Virtudes cardinales } \\
\text { Sentidos corporales } \\
\text { Potencias del alma } \\
\text { Dones Espíritu Santo } \\
\text { Frutos Espíritu Santo } \\
\text { Bienaventuranzas } \\
\text { Novisimos }\end{array}$ & $\begin{array}{c}10 \\
6 \\
1 \\
1 \\
4\end{array}$ & $\begin{array}{r}10 \\
x \\
3 \\
\\
x \\
1 \\
3 \\
x \\
x \\
12\end{array}$ & $\begin{array}{l}3 \\
1\end{array}$ & & & & \\
\hline $\begin{array}{l}\text { I. Confesión general } \\
\text { Acto de contrición } \\
\text { Oración breve } \\
\text { Actos de fe, esper., caridad } \\
\text { Rosario } \\
\text { Letanía } \\
\text { Oración del Sudario } \\
\text { Oración a S. José } \\
\text { Modo de ayudar a Misa } \\
\text { Máximas evangélicas }\end{array}$ & & $\begin{array}{l}\mathrm{x} \\
\mathrm{x} \\
\mathrm{x}\end{array}$ & $\mathbf{x}$ & $\mathbf{x}$ & $\mathrm{x}$ & $\mathrm{x}$ & . \\
\hline Total & 326 & 199 & 113 & 7 & 4 & 3 & \\
\hline \multicolumn{8}{|c|}{$(x)=$ formulario escueto, sin preguntas } \\
\hline
\end{tabular}


DE LAS PREGUNTAS DEL CATECISMO DE RIPALDA

\begin{tabular}{|c|c|c|c|c|c|}
\hline \multirow{2}{*}{ CATECISMO DE RIPALDA } & \multicolumn{5}{|c|}{$\mathrm{N}^{\circ}$ preguntas } \\
\hline & Total & Ripalda & $\begin{array}{r}\text { Suprimidas } \\
\text { a Ripalda }\end{array}$ & De la Riva & Anónimas \\
\hline A. Texto de la Doctrina Cristiana & - & - & - & - & - \\
\hline B. Principio de la Doc. Cristiana & 19 & 17 & & 2 & \\
\hline C. Obligaciones del cristiano & 10 & 10 & & & \\
\hline D. El Credo & 13 & 10 & 2 & 1 & \\
\hline E. Artículos de la fe & 20 & 19 & 1 & & \\
\hline F. Artículos de la Santa Humanidad & 43 & 20 & 2 & 18 & 3 \\
\hline G. Padrenuestro & 29 & 23 & 1 & 5 & \\
\hline H. Otras oraciones & 11 & 9 & & 2 & \\
\hline I. Ave María y Salve & 13 & 13 & & & \\
\hline $\begin{array}{l}\text { J. Mandamientos de Dios } 1 .^{\circ} \\
2 .^{\circ} \\
3 .^{\circ} \\
4 .^{\circ} \\
5 .^{\circ} \\
6 .^{\circ} \\
7 .^{\circ} \\
8 .^{\circ} \\
9 .^{\circ} \mathrm{y} 10 .^{\circ}\end{array}$ & $\begin{array}{r}14 \\
16 \\
5 \\
10 \\
6 \\
7 \\
8 \\
10 \\
5\end{array}$ & \begin{tabular}{r|r}
7 \\
11 \\
3 \\
7 \\
3 \\
6 \\
4 \\
3 \\
3
\end{tabular} & & $\begin{array}{l}7 \\
4 \\
2 \\
3 \\
3 \\
1 \\
4 \\
7 \\
2 \\
\end{array}$ & 1 \\
\hline K. Otros mandamientos & 6 & 6 & & & \\
\hline $\begin{array}{l}\text { L. Mandamientos de la Iglesia } \\
1 .^{\circ} \\
2 .^{\circ} \text { y } 3 .^{\circ} \\
4 i^{\circ} \\
5 .^{\circ}\end{array}$ & $\begin{array}{r}7 \\
8 \\
5 \\
12 \\
2\end{array}$ & $\begin{array}{l}4 \\
7 \\
2 \\
6 \\
2\end{array}$ & & $\begin{array}{l}2 \\
1 \\
3 \\
1\end{array}$ & 1 \\
\hline $\begin{array}{l}\text { M. Sacramentos } \\
\text { Bautismo } \\
\text { Confirmación } \\
\text { Penitencia } \\
\text { Eucaristía } \\
\text { Unción de enfermos } \\
\text { Orden } \\
\text { Matrimonio } \\
\end{array}$ & $\begin{array}{r}6 \\
9 \\
5 \\
29 \\
18 \\
6 \\
3 \\
6 \\
\end{array}$ & \begin{tabular}{r|r}
5 \\
3 \\
2 \\
10 \\
11 \\
3 \\
1 \\
1 \\
\end{tabular} & & $\begin{array}{r}6 \\
3 \\
14 \\
7 \\
3 \\
2 \\
5 \\
\end{array}$ & 1 \\
\hline $\mathrm{N}$. Indulgencias & 9 & 4 & & 5 & \\
\hline O. Obras de misericordia & 5 & 5 & & & \\
\hline P. Enemigos del alma & 15 & 13 & & 2 & \\
\hline Q. Pecados y virtudes & 35 & 29 & 2 & 4 & \\
\hline R. Virtudes teologales & 12 & 10 & & 2 & \\
\hline S. Virtudes cardinales & 14 & 11 & & 2 & 1 \\
\hline T. Potencias del alma & 5 & 4 & & 1 & \\
\hline U. Sentidos corporales & 1 & 1 & & & \\
\hline V. Dones del Espíritu Santo & 15 & 8 & & 7 & \\
\hline X. Frutos del espíritu Santo & 16 & & & 14 & 2 \\
\hline Y. Bienaventuranzas & 18 & 12 & & 6 & \\
\hline Tot a 1 & 506 & 328 & 8 & 151 & 19 \\
\hline
\end{tabular}




\section{SÍNTESIS DE LAS COINCIDENCIAS O INFLUENCIAS ENTRE JERÓNIMO DE RIPALDA Y GASPAR ASTETE}

- Origen apostólico del Credo, autoridad de Dios revelador y mediación de la Iglesia en la transmisión a los hombres.

- Coincidencia básica en la definición ofrecida de Dios.

- Influencia en la expresión de la concepción de Jesús, llevada a cabo «sobrenatural y milagrosamente».

- Cuestiones relativas al descenso de Cristo a los infiernos.

- Explicación relativas a la resurrección de Jesús.

- Glorificación de Cristo a la derecha del Padre.

- Influencia en las expresiones empleadas para describir la comunión de los santos.

- Coincidencia al hablar del origen del padrenuestro, su finalidad, así como la definición de oración.

- Orden y contenido de las preguntas relativas al Ave María y la Salve.

- Cuestiones relativas al juramento en vano, a evitar jurar por las criaturas y el remedio para no jurar.

- El honrar a los padres y por extensión a los superiores.

- Explicación del quinto mandamiento.

- Explicaciones del sexto mandamiento.

- Obligación que impone el séptimo mandamiento.

- Enumeración de las nueve obras que perdonan los pecados veniales.

- Aclaración del término «obras de misericordia» y explicación de las ocasiones en que su cumplimiento constituye una obligación.

- Definición de pecado mortal.

- Los pecados capitales, su malicia y las oportunidades en que constituyen pecados contra la caridad.

- Explicación relativa a las potencias del alma.

- Explicación relativa a los sentidos corporales.

- Explicación relativa a las bienaventuranzas. 


\section{INFLUENCIAS EJERCIDAS POR JERÓNIMO DE RIPALDA SOBRE GABRIEL MENÉNDEZ DE LUARCA}

- Necesidad de saber "y entender» las obligaciones del cristiano.

- Exposición del fin último del hombre.

- Calificativo de la muerte «eterna» como consecuencia del pecado y modo de incurrir en ella.

- Condiciones de la oración.

- Mención de las reliquias de los santos como dignas de veneración.

- Obligación, incluida dentro del primer mandamiento de la ley de Dios de observar las virtudes de fe, esperanza y caridad.

- Condiciones para la licitud del juramento según verdad, justicia y necesidad.

- Remitir a la práctica observada "entre gentes de buena conciencia» de cenar sin romper la ley del ayuno.

- Ausencia del pan y del vino en la eucaristía, substituida por la presencia de Cristo, subsistiendo los accidentes de pan y vino.

INFLUENCIA EJERCIDA POR UN CORRECTOR ANÓNIMO DEL CATECISMO DE RIPALDA SOBRE GABRIEL MENÉNDEZ DE LUARCA

- Distinción entre las clases de contrición.

\section{INFLUENCIA EJERCIDAS POR GASPAR ASTETE SOBRE JUAN ANTONIO DE LA RIVA}

- Inclusión de la pregunta relativa al nombre de Jesús y explicación del sentido de la salvación que nos trae.

- Referencia a las explicaciones del credo no contenidas en los artículos de la fe.

- Significado de la palabra «amén» al final del padrenuestro.

- Aclaración global, incluida en el primer mandamiento de la ley de Dios, de que ama a Dios quien cumple sus mandamientos.

- Alusión a la superstición, en el primer mandamiento de la ley de Dios.

- Referencia al juicio temerario ( $8^{\circ}$ mandamiento).

- Invitación al dolor de los pecados por parte de quien se encuentra en pecado mortal.

- Cómo huir del demonio y de la carne.

- Concepto de «mortal» aplicado al pecado.

- Exposición de los afectos que produce la unción de los enfermos. 


\section{INFLUENCIAS EJERCIDAS POR GABRIEL MENÉNDEZ DE LUARCA SOBRE JUAN ANTONIO DE LA RIVA}

- Descripción del constitutivo substancial de Cristo (naturalezas, entendimientos, voluntades, personas, memorias).

- Modo de realizarse la concepción de Cristo.

- Descripción de las clases de oración.

- Lugares de localización de la presencia de Cristo.

- Observancia de la fe, esperanza y caridad en el primer mandamiento de la ley de Dios.

- Fundamento necesario para poder emitir un juicio, y obligación consecuente de restituir la fama si el juicio emitido es falso.

- Suficiencia del dolor de atrición para la confesión.

- Necesidad de un acto de perfecta contrición en el caso de no poder confesarse.

- Conducta a seguir en la confesión cuando sólo se tienen pecados veniales.

- Contenido real en la hostia y el cáliz después de la consagración.

- Descripción del alma humana, sede de las potencias correspondientes.

L. Resines 